\title{
An atmospheric tape recorder: The imprint of tropical tropopause temperatures on stratospheric water vapor
}

\author{
Philip W. Mote, ${ }^{1,2}$ Karen H. Rosenlof,,$^{3,4}$ Michael E. McIntyre, ${ }^{5}$ \\ Ewan S. Carr, ${ }^{1,6}$ John C. Gille, ${ }^{7}$ James R. Holton, ${ }^{8}$ Jonathan S. Kinnersley, ${ }^{1,9}$ \\ Hugh C. Pumphrey, ${ }^{1}$ James M. Russell III, ${ }^{10}$ and Joe W. Waters ${ }^{11}$
}

\begin{abstract}
We describe observations of tropical stratospheric water vapor $q$ that show clear evidence of large-scale upward advection of the signal from annual fluctuations in the effective "entry mixing ratio" $q_{\mathrm{E}}$ of air entering the tropical stratosphere. In other words, air is "marked," on emergence above the highest cloud tops, like a signal recorded on an upward moving magnetic tape. We define $q_{\mathrm{E}}$ as the mean water vapor mixing ratio, at the tropical tropopause, of air that will subsequently rise and enter the stratospheric "overworld" at about $400 \mathrm{~K}$. The observations show a systematic phase lag, increasing with altitude, between the annual cycle in $q_{\mathrm{E}}$ and the annual cycle in $q$ at higher altitudes. The observed phase lag agrees with the phase lag calculated assuming advection by the transformed Eulerian-mean vertical velocity of a $q_{\mathrm{E}}$ crudely estimated from $100-\mathrm{h} \mathrm{Pa}$ temperatures, which we use as a convenient proxy for tropopause temperatures. The phase agreement confirms the overall robustness of the calculation and strongly supports the tape recorder hypothesis. Establishing a quantitative link between $q_{\mathrm{E}}$ and observed tropopause temperatures, however, proves difficult because the process of marking the tape depends subtly on both small- and large-scale processes. The tape speed, or large-scale upward advection speed, has a substantial annual variation and a smaller variation due to the quasi-biennial oscillation, which delays or accelerates the arrival of the signal by a month or two in the middle stratosphere. As the tape moves upward, the signal is attenuated with an $e$-folding time of about 7 to 9 months between 100 and $50 \mathrm{hPa}$ and about 15 to 18 months between 50 and $20 \mathrm{hPa}$, constraining possible orders of magnitude both of vertical diffusion $K_{z}$ and of rates of mixing in from the extratropics. For instance, if there were no mixing in, then $K_{z}$ would be in the range $0.03-0.09 \mathrm{~m}^{2} \mathrm{~s}^{-1}$; this is an upper bound on $K_{z}$.
\end{abstract}

\footnotetext{
${ }^{1}$ Department of Meteorology, University of Edinburgh, Edinburgh, Scotland.

${ }^{2}$ Also at U.K. Universities' Global Atmospheric Modelling Programme, Reading, England.

${ }^{3}$ Cooperative Institute for Research in Environmental Sciences, University of Colorado/NOAA, Boulder, Colorado.

${ }^{4}$ Also at Aeronomy Laboratory, Environmental Research Laboratories, NOAA, Boulder, Colorado.

${ }^{5}$ Centre for Atmospheric Science at the Department of Applied Mathematics and Theoretical Physics, University of Cambridge, Cambridge, England.

${ }^{6}$ Now at Logica Ltd., London, England.

${ }^{7}$ Atmospheric Chemistry Division, National Center for Atmospheric Research, Boulder, Colorado.

${ }^{8}$ Department of Atmospheric Sciences, University of Washington, Seattle.

${ }^{9}$ Now at Department of Applied Mathematics, University of Washington, Seattle.

${ }^{10}$ NASA Langley Research Center, Hampton, Virginia.

${ }^{11}$ Jet Propulsion Laboratory, Pasadena, California.
}

Copyright 1996 by the American Geophysical Union.

Paper number 95JD03422.

0148-0227/96/95JD-03422\$05.00

\section{Introduction}

It is well known that the annual cycle in water vapor mixing ratio $q$ at the tropical tropopause appears to spread sideways to middle latitudes, with a certain phase lag. This is shown, for instance, by data from radiosondes [Mastenbrook and Oltmans, 1983; Hyson, 1983], from the Stratospheric Aerosol and Gas Experiment (SAGE) II [McCormick et al., 1993], and from aircraft observations [Hintsa et al, 1994]. For the tropical lower stratosphere itself, Mastenbrook and Oltmans [1983] called attention to Mastenbrook's [1968] soundings at Trinidad $\left(11^{\circ} \mathrm{N}, 60^{\circ} \mathrm{W}\right)$, which showed a deepening dry layer during northern winter and spring. Kley et al. [1979] noted a decrease of $q$ with height from the tropopause to $19 \mathrm{~km}$ in a balloon sounding above Brazil in August. They suggested a few possible explanations, one of which attributed the minimum at $19 \mathrm{~km}$ to upward advection of the low $q$ values that presumably existed at the tropopause 6 months earlier. Other in situ observations of $q$ have shown layered structures in the tropical lower stratosphere at various times [Kley et al., 1982; Kelly et al., 1993; Vömel et al., 1995; Wein- 
stock et al., 1995; J. Ovarlez et al., In situ water vapour measurement, and a case study of the drying mechanism of the tropical lower stratosphere, submitted to Quarterly Journal of the Royal Meteorological Society, 1995, hereinafter referred to as Ovarlez et al., submitted manuscript, 1995].

At a NATO workshop on stratosphere-troposphere exchange in September 1993, one of us (M.E.M.) argued that such tropical lower stratospheric $q$ features should be part of a larger spatio-temporal pattern with a very simple phase lag structure. Air passing the tropopause, and carried upward in the large-scale stratosplieric mean circulation, should be marked with the entry mixing ratio $q_{E}$ in the same way as a magnetic tape is marked by the recording head. The variablespeed "motor" driving the "tape" is the well known extratropical wave driving of the large-scale mean circulation, in which the extratropical stratosphere and mesosphere act together as a global-scale suction pump on the tropical lower stratosphere [e.g., Holton et al., 1995, and references therein], with seasonally and interannually variable strength [Rosenlof and Holton, 1993; Yulaeva et al., 1994].

Direct evidence in support of this tape recorder hypothesis has recently become available from observations of $q$ by the Microwave Limb Sounder (MLS) instrument on the Upper Atmosphere Research Satellite (UARS) [Mote ct al., 1995]. The larger-scale view revealed by the MLS data showed what looked like the signature of upward advection of $q$ features by the mean circulation, seemingly little degraded by mixing. Mote et al. [1995] checked this by using observed ozone, water vapor, and temperature, together with a state-of-the-art radiation scheme, to calculate a transformed Eulerian-mean (TEM) circulation and running two-dimensional (2-D) backward trajectories from various latitudes and heights in the stratosphere down to $100 \mathrm{hPa}$. The $q$ for the entire trajectory was then estimated as a saturation value $q_{\mathrm{s}}$ based on gridded 100hPa temperatures. The $q$ values observed by MLS varied with time in a way sufficiently like that of the 2-D t.rajectory calculation to confirm, or at least to demonstrate consistency with, a tape-recorder-like connection between those $q$ values and the annual cycle in tropopause temperature.

There are a number of questions about the tape recorder hypothesis that were not answered by Mote et al. [1995]. They found a large discrepancy in the amplitude of the observed $q$ variations and the estimated tape signal. What was the cause of this amplitude discrepancy? Would observations at altitudes below 46 $\mathrm{hPa}$, beyond the range of the standard MLS retrieval algorithm, show the same kind of pattern? Can mixing effects be quantified? What is the effect of the quasibiennial oscillation (QBO)?

In this paper we address these questions with the help of additional data and calculations. Some of the data come from three instruments aboard UARS: MLS, with an improved water vapor retrieval, the Halogen Occultation Experiment (HALOE), and the Cryogenic
Limb Array Etalon Spectrometer (CLAES). Also used are data from the Stratospheric Aerosol and Gas Experiment (SAGE II) aboard the Earth Radiation Budget Satellite, from the NOAA Lyman $\alpha$ hygrometer aboard the NASA ER-2 aircraft, and from radiosondes. The sources of data are described in section 2 . In section 3 we use these data and some calculations to examine in more detail whether the tape recorder hypothesis does indeed explain the observations. In particular, we look at the QBO effects (section 3.1), at some possible causes of the amplitude discrepancy (section 3.2) and at the role of mixing in attenuating the tape signal (section 3.3). Section 3.2 focuses on the relationship between $100-\mathrm{hPa}$ temperatures (as obtained, for convenience, from the United Kingdom Meteorological Office (UKMO)) and observed $q$ in the stratosphere. For this purpose we define $q_{\mathrm{E}}$ as the mean water vapor mixing ratio, at the tropical tropopause, of air that will subsequently rise and enter the stratospheric "overworld" at around $400 \mathrm{~K}$ or $83 \mathrm{hPa}$. Air that reaches the tropopause but fails to get into the overworld, by returning to the troposphere either downward or poleward, for example, will therefore not affect $q_{\mathrm{E}}$.

\section{Data Sources and Treatment}

Because each instrument has different observational characteristics, we have used differeni methods of presenting the data from each instrument. The shoice of latitude limits to define the tropics is not very critical. As was shown by Carr et al. [1995], $q$ has small meridional variations between about $15^{\circ} \mathrm{S}$ and $15^{\circ} \mathrm{N}$, so temporal variations ten's to be in phase. Poleward of those approximate limits, $q$ has a sharp gradient beyond which annual variations are small and are not as well correlated with tropical annual variations.

Gaps in the UARS data record appear at various points. The longest gap occurred during the period June 2 to July 15,1992 , when problems with the drive for UARS's solar array kept the instruments from functioning. The MLS water vapor radiometer was turned off for most of this period, and HALOE was turned off for the first few weeks.

Because of methane oxidation, which produces water, there is generally an increase of water vapor with height in the stratosphere, and this increase makes it difficult to relate annual variations at different levels. This difficulty can be alleviated by using twice methane plus water, $2\left(\mathrm{CH}_{4}\right)+\left(\mathrm{H}_{2} \mathrm{O}\right)$, in place of water, because methane oxidation has a conversion efficiency very close to 2 [e.g., Dessler et al. 1994]. The quantity $2\left(\mathrm{CH}_{4}\right)+\left(\mathrm{H}_{2} \mathrm{O}\right)$ (hereinafter called $\hat{H}$, as suggested by Jones et al. [1986]) is the variable part of "total hydrogen," $2\left(\mathrm{CH}_{4}\right)+\left(\mathrm{H}_{2} \mathrm{O}\right)+\left(\mathrm{H}_{2}\right)$, since $\left(\mathrm{H}_{2}\right)$ is nearly constant at about $\frac{1}{2}$ part per million by volume (ppmv) in the lower and middle stratosphere [e.g., Dessler et al. 1994]. HALOE and CLAES both retrieve methane and we can plot $H$ for those instruments (though because of problems with CLAES $\mathrm{H}_{2} \mathrm{O}$ we do not do so 
for CLAES). MLS and SAGE II do not, however, retrieve methane, so we must follow a somewhat cruder approach and subtract the time mean vertical profile, where the time mean is taken over the entire record in each case.

\subsection{Microwave Limb Sounder (MLS)}

MLS vertically scans the Earth's limb and measures atmospheric thermal radiance at millimeter wavelengths, from which vertical profiles of atmospheric parameters are retrieved. The measurement technique is described by Waters [1993], and the instrument is described by $B$ arath et al. [1993]. Stratospheric water vapor profiles were obtained from the MLS $183-\mathrm{GHz}$ radiometer, which operated from late September 1991 through late April 1993. The tropics were observed continuously (with few exceptions) during this period, and approximately 240 profiles between $12^{\circ} \mathrm{S}$ and $12^{\circ} \mathrm{N}$ were obtained each day. The estimated accuracy is better than $20 \%$, and individual profile points have precisions of 0.2 to $0.4 \mathrm{ppmv}$ [Lahoz et al., 1996]. Since hundreds of profiles are averaged for our analyses, the observational results presented here should have very good precision.

For the standard version 3 retrieval, the vertical profiles are piecewise linear, with nodes (grid points) separated by a factor of $10^{1 / 3}$ in atmospheric pressure. This gives levels at $100,46,22$, and $10 \mathrm{hPa}$ in the lower stratosphere, separated by approximately $5.3 \mathrm{~km}$. A climatology based on Limb Infrared Monitor of the Stratosphere (LIMS) data [Gille and Russell, 1984] is used as a priori data for the retrieval, and the a priori standard deviation is 2 ppmv. A strict opacity criterion is imposed that prevents radiances being used if the atmosphere is too opaque at $183 \mathrm{GHz}$ along the line of sight; this opacity criterion must be imposed because the version 3 retrieval is linear, that is, radiances are presumed to be proportional to the concentration of water vapor in the tangent layer. As a result of the opacity criterion, the $46-\mathrm{hPa}$ level is the lowest level for which water vapor is retrieved.

To overcome this limitation, we reprocessed tropicai MLS data for a number of days (at approximately 10day intervals) using a different, nonlinear procedure. We used a grid with twice as many levels, that is, with nodes separated by a factor of $10^{1 / 6}$ in atmospheric pressure, or about $2.7 \mathrm{~km}$; this grid is more closely spaced than the theoretical resolution of MLS, which is about $3.5 \mathrm{~km}$, but we can still retrieve a profile (as described below). The finer grid has levels at 100, 68, $46,32,22,15$, and $10 \mathrm{hPa}$ in the lower stratosphere. As a priori data for the retrieval we used a revised climatology based on SAGE II, and the a priori standard deviation was 3.5 ppmv. Lest the monthly mean climatology introduce an artificial seasonality, we used the January climatology as the a priori throughout the year. Instead of imposing the opacity criterion, we used a nonlinear, iterative retrieval that (fortunately) requires only a few iterations in the tropical lower stratosphere. At each iteration we recalculated only a few of the processing coefficients instead of the full set. We ascertained that this is a reasonable approximation to the full nonlinear retrieval by comparing the two approaches for one orbit; the agreement was excellent in the tropical lower stratosphere, although it was poor in the polar regions and in the mesosphere. The a priori covariance matrix has some nonzero off-diagonal elements that smooth the retrieved profile just enough to prevent computational instabilities. (An element $S_{i j}$ of the covariance matrix represents the covariance between errors at retrieval levels $i$ and $j$; use of a diagonal covariance matrix would mean that errors at different levels are assumed to be uncorrelated. With a grid finer than the instrument's theoretical vertical resolution, no unique solution exists, but if off-diagonal elements of the covariance matrix are nonzero, then the retrieval is lightly constrained to produce a smooth profile rather than a jagged profile.)

The results of this procedure should be regarded as preliminary for at least two reasons. First, they use MLS version 3 temperature and pressure values, which have known minor problems (these will be reduced in future versions of the data). Second, the detailed error analyses that have been carried out on version 3 data have not been performed on the data shown in this paper.

We are confident, however, that the results given here represent a real improvement over version 3 . The error ratio, that is, the ratio of retrieved error to a priori standard deviation, is small even at $68 \mathrm{hPa}$ and usually also at $100 \mathrm{hPa}$, indicating good data (and minimal reliance on the a priori data) at those levels. The finer vertical resolution is crucial to resolving the tape signal, as was apparent from the weak visual connection between extrema at 46 and $22 \mathrm{hPa}$ in Figure 1a of Mote et al. [1995].

\subsection{Halogen Occultation Experiment (HALOE)}

HALOE (described by Russell et al. [1993]) is a solar occultation instrument that, because of the inclination of the UARS orbit, samples the atmosphere about 30 times per day, half at one latitude at sunrise and half at another latitude at sunset. These two observation latitudes change with time as the UARS orbit precesses, so the tropical observations shown are actually taken at irregular intervals (see Figure 2) but are binned by month for Plate 1. HALOE's orbital characteristics prevent it from viewing the tropics at all in some months. But HALOE has an important advantage in that it does not require an absolute radiance calibration in order to make its measurements. Instead, it calculates the ratio of the solar intensity measured through the atmosphere at the Earth's limb to the unattenuated solar intensity measured above the atmosphere. Consequently, the experiment provides very precise data that are well suited for time trend studies. We use HALOE version 17 data; the version 17 retrieval algorithm represents a marked improvement over earlier versions. The effective vertical weighting of HALOE measurements is about $2 \mathrm{~km}$, but the data are shown on a vertical grid of $1.3 \mathrm{~km}$ for Plate $1 \mathrm{~b}$ and of $0.2 \mathrm{~km}$ for Figure 1 . 


\subsection{Cryogenic Limb Array Etalon Spectrometer (CLAES)}

CLAES (described by Roche et al. [1993]) is a limbviewing spectrometer that measures the infrared emission by several gases and by aerosols. In order to reduce overlap and interference between gases, CLAES uses high spectral resolution, which requires that the instrument be cooled to temperatures of $15-130 \mathrm{~K}$ (by solid neon and solid carbon dioxide) to allow narrow-band measurements to be made with high signal-to-noise ratios. CLAES provides data every $500 \mathrm{~km}$ along the orbit, with a vertical resolution of $2.5 \mathrm{~km}$, spanning 50 $\mathrm{km}$ in altitude from a nominal lower level at $10-15 \mathrm{~km}$. Because of the opacity of atmospheric features at low altitudes and the effects of the Pinatubo aerosols, the retrievals at altitudes below $46 \mathrm{hPa}$ are not as reliable as those at higher altitudes. We use CLAES version 7 water vapor data, omitting values at $46 \mathrm{hPa}$ before July 1992 because they appear to be contaminated by aerosol.

\subsection{Stratospheric Aerosol and Gas Experiment (SAGE II)}

The characteristics of the SAGE II water vapor retrieval and measurements are described by Rind et al. [1993]. Like HALOE, SAGE II is a self-calibrating solar occultation instrument. It has a nominal vertical resolution of $1 \mathrm{~km}$ and provides the most extensive available water vapor data set, extending in time from 1985 to 1991 , in latitude from about $70^{\circ} \mathrm{N}$ to $70^{\circ} \mathrm{S}$ and in altitude from the surface to $120 \mathrm{~km}$. SAGE II uses the $0.94 \mu \mathrm{m}$ wavelength near-infrared channel to derive water vapor mixing ratios. Because many aerosol particles are a substantial fraction of a wavelength in diameter and therefore strongly scatter the near-infrared radiation, too much aerosol makes the retrieval of water vapor impossible. In the tropical lower stratosphere there is always enough aerosol between 20 and $25 \mathrm{~km}$ to make retrievals very noisy at best. Following the eruption of Mount Pinatubo in June 1991, the enhanced volcanic aerosol catastrophically interfered with the SAGE II water vapor retrievals, which were therefore discontinued. Note incidentally that the aerosol problem has little effect on the midlatitude results of McCormick et al. [1993], which were for the years 1986-1988.

The SAGE II data set available to us extended from January 1986 to May 1991, 65 months of data. Tropical water vapor data in the lower stratosphere show a steady decrease that is not fully understood (E.W. Chiou, personal communication, 1994). As with HALOE, SAGE II does not sample the full range of latitudes in every month and, in particular, it samples the tropics for only a few days each month.

In attempting to increase the signal-to-noise ratio enough to find the tape signal, we took advantage of the length of the SAGE II record and averaged the years together as follows. After discarding water vapor observations whose retrieved error exceeded half the value of the water vapor mixing ratio itself, we binned the ob- servations by latitude in $5^{\circ}$ bins, detrended the data for each altitude grid point in each bin, and then binned the observations by calendar month to find a mean annual cycle. Then we calculated the annual and semiannual harmonics and added them to produce a smoothed annual cycle. Then those bins and altitudes for which the original mean annual cycle is well represented by the smoothed annual cycle were used to form a tropical average from $15^{\circ} \mathrm{S}$ to $15^{\circ} \mathrm{N}$. "Well represented" here means that the correlation coefficient between the original annual cycle and the smoothed annual cycle exceeded 0.5 . This excludes most of the bins in the aerosol layer, that is, between about 20 and $25 \mathrm{~km}$. Note that in regions where a well-represented annual cycle does not exist, this method will produce a temporally constant value of zero.

\subsection{Lyman $\alpha$ Instrument Aboard the ER-2}

In October 1994 the NASA ER-2 aircraft made a few flights near the equator, as part of the Airborne Southern Hemisphere Ozone Experiment/Measurements for Assessing the Effects of Stratospheric Aircraft (ASHOE/MAESA) campaign. The NOAA Lyman $\alpha$ hygrometer [Kelly et al., 1989] measures total water by first vaporizing any ice, then photodissociating the vapor, and then finding the intensity of the resulting fluorescence. In the absence of cloud ice, the hygrometer simply measures water vapor. Because no noticeable cloud ice was present at the altitudes examined here, the results we present show water vapor only.

\section{Results and Discussion}

Plate 1 shows time-height sections of deviation from time mean water vapor mixing ratio $q$ for MLS (Plate 1a) and for SAGE II (Plate 1c), and of $\hat{H}=2\left(\mathrm{CH}_{4}\right)+$ $\left(\mathrm{H}_{2} \mathrm{O}\right)$ for HALOE (Plate 1b). For MLS we show daily averages at roughly 10-day intervals for the new, nonlinear retrieval, from October 1991 to April 1993. For HALOE we show monthly means from October 1991 to July 1995. The SAGE figure shows two cycles of the annual and semiannual harmonics of the 1986-1991 detrended mean $q$, as was discussed in section 2.4.

The new MLS $q$ (Plate 1a) clearly suggests the upward advection of successive minima and maxima - far more clearly than the standard version 3 -and indicates that the transit time from $100 \mathrm{hPa}$ to $46 \mathrm{hPa}$ is 6 months or more. (Recall that altitudes below $46 \mathrm{hPa}$ are beyond the range of the version 3 retrieval.) With the new retrieval, MLS not only provides information on the lowest $5 \mathrm{~km}$ of the stratosphere, but also provides higher vertical resolution throughout the stratosphere.

HALOE has twice the vertical resolution of even the new MLS retrieval and retrieves methane as well, hence $\hat{H}$. As discussed above, $\hat{H}$ shows the tape signal directly, without having to subtract the time mean. Plate 1b shows minima and maxima in $\hat{H}$ traveling upward as in Plate $1 \mathrm{a}$, and confirms the long transit time from 100 $\mathrm{hPa}$ to $46 \mathrm{hPa}$. Plates $1 \mathrm{a}$ and $\mathrm{lb}$ also suggest that $q$ fea- 


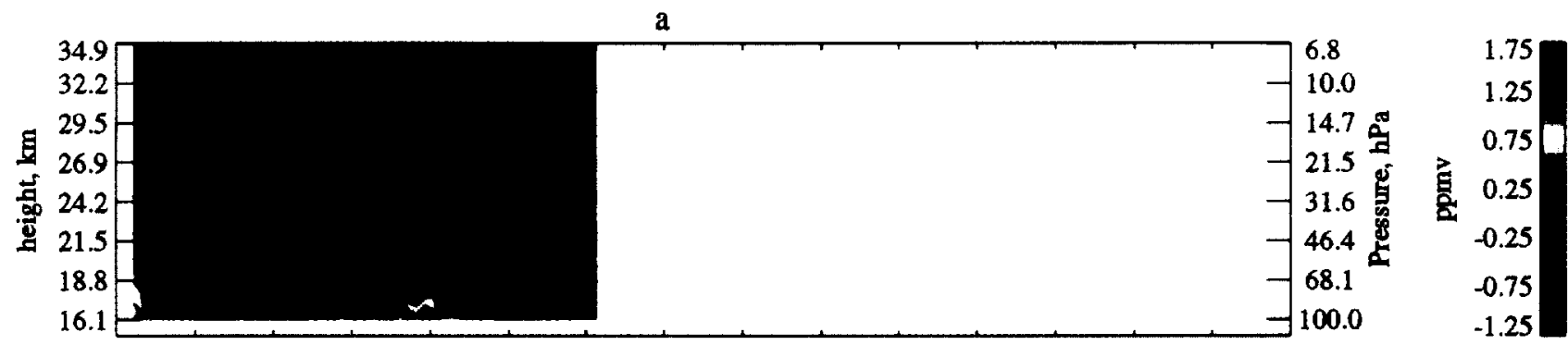

Oct 91 Jan 92 Apr Jul Oct Jan 93 Apr Jul Oct Jan 94 Apr Jul Oct Jan 95 Apr Jul

b
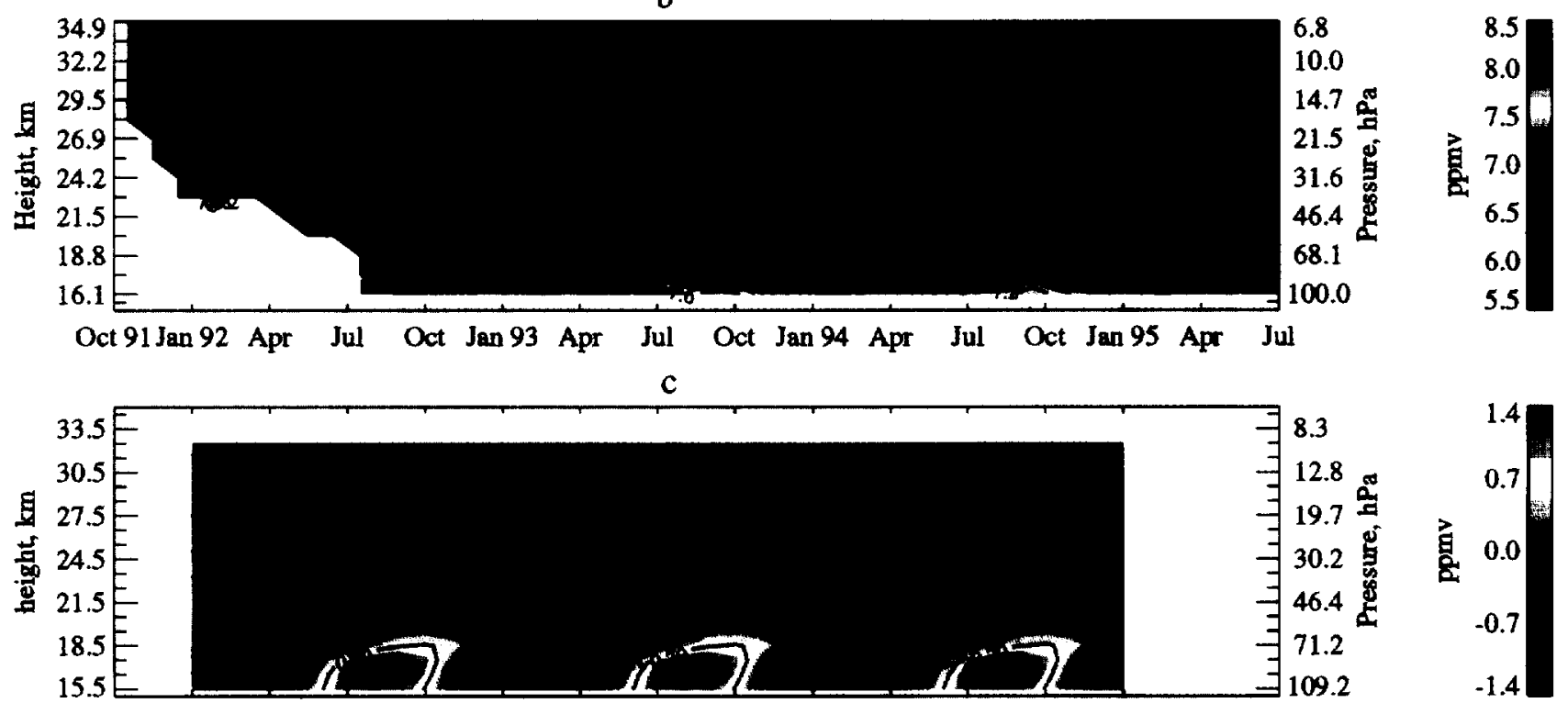

Jan Apr Jul Oct Jan Apr Jul Oct Jan Apr Jul Oct Jan

d

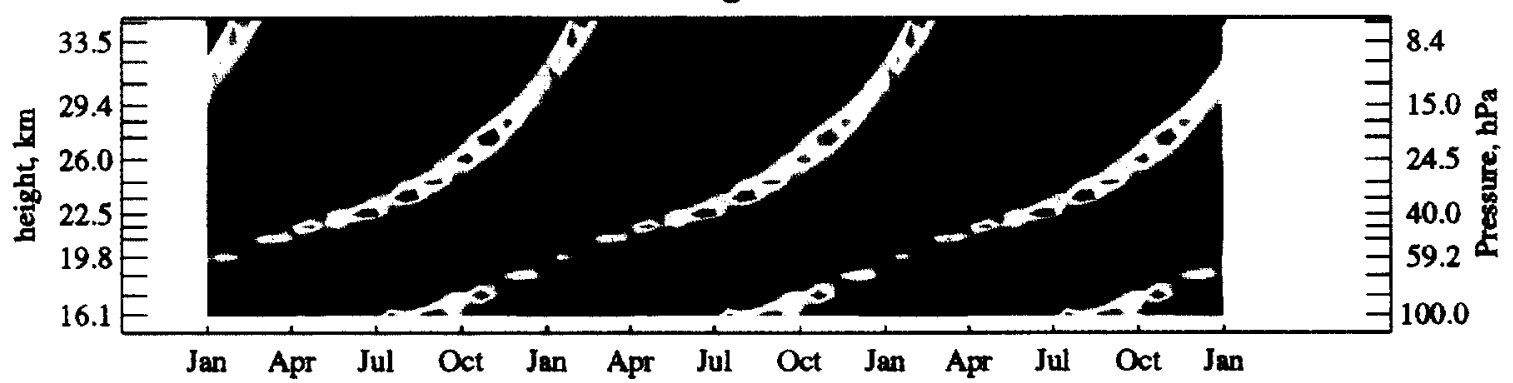

Plate 1. Time-height sectıons of (a) MLS water vapor mixing ratio $q$ shown as the deviation from the time-mean profile, between $12^{\circ} \mathrm{S}$ and $12^{\circ} \mathrm{N} ;(\mathrm{b}) \mathrm{HALOE} \hat{H}=2\left(\mathrm{CH}_{4}\right)+\left(\mathrm{H}_{2} \mathrm{O}\right)$, the variable part of total hydrogen, between $12^{\circ} \mathrm{S}$ and $12^{\circ} \mathrm{N}$; (c) SAGE II water vapor mixing ratio $q$, annual and semiannual Fourier harmonics for January 1986 to May 1991 , between $15^{\circ} \mathrm{S}$ and $15^{\circ} \mathrm{N}$ (retrieval affected by aerosol layer, 20-25 km); and (d) TEM 2-D back-trajectory calculation of $q$ (see text). For each panel, tick marks on the ordinate indicate the vertical grid points used, and the color scheme is as indicated in the color bar to the right. This figure is available on the Internet at web site http://www.damtp.cam.ac.uk/atmos-dynamics, or by anonymous ftp from ftp.damtp.cam.ac.uk, cd pub/papers/mem, get tapel.ps. 


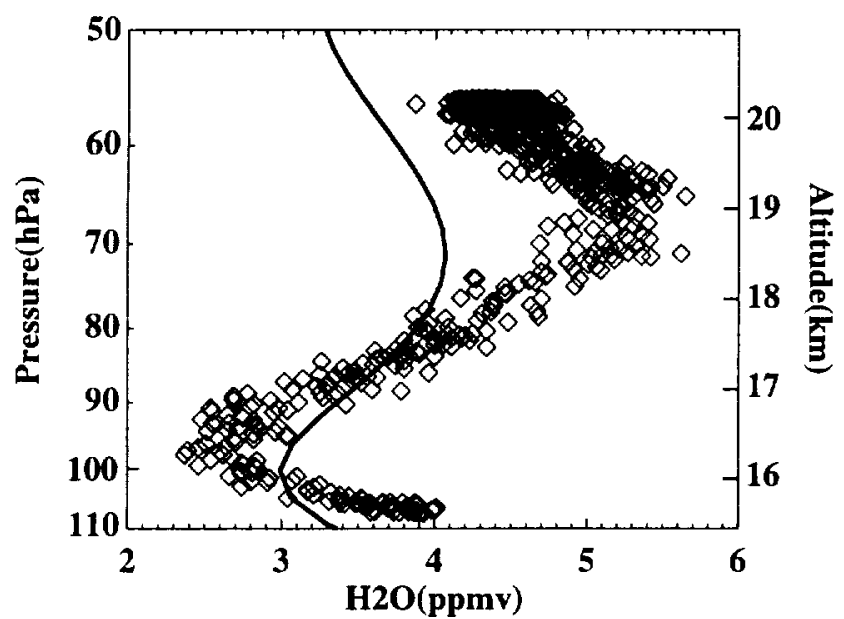

Figure 1. Vertical profiles of water vapor $q$ measured by the NOAA Lyman $\alpha$ hygrometer flying on the ER-2 aircraft (diamonds) and by HALOE (solid line). The Lyman- $\alpha$ profile is from a tropical dive of the aircraft on October 29,1994 , in the latitude range $2.2^{\circ} \mathrm{N}$ to $2.2^{\circ} \mathrm{S}$ and longitude range $158.0^{\circ} \mathrm{W}$ to $158.6^{\circ} \mathrm{W}$. The HALOE profile is an average of measurements made between November 1, 1994, and November 13, 1994, in the latitude range $5^{\circ} \mathrm{N}$ to $5^{\circ} \mathrm{S}$ and longitude range $180^{\circ}$ to $140^{\circ} \mathrm{W}$.

tures travel upward relatively quickly during northern winter (about $0.4 \times 10^{-3} \mathrm{~m} \mathrm{~s}^{-1}$ ) and relatively slowly during the rest of the year (about $0.2 \times 10^{-3} \mathrm{~m} \mathrm{~s}^{-1}$ ). We will return to this point in section 3.1 . The amplitude of the tape signal diminishes sharply between the tropopause and about $50 \mathrm{hPa}$ but diminishes much less between 50 and $20 \mathrm{hPa}$. The high and low $\hat{H}$ values seem to be rather variable from month to month, but this may be due to poor sampling; see Figure 2 below. We will draw new inferences about mixing from these observations in section 3.3 .

In SAGE II (Plate 1c), the tape signal is not as clear as in MLS and HALOE, because of the difficulty of observing $q$ in the aerosol layer $(20-25 \mathrm{~km}$ or so). Relatively dry air leaves the tropopause in a period centered around February, and relatively moist air leaves in a period centered around August; some months later these features are still evident at $19 \mathrm{~km}$. The tape signal, however, is almost invisible in the aerosol layer. Only a vestige seems to be visible as a dry (moist) anomaly at $22 \mathrm{~km}$ in December (June), consistent with MLS, HALOE, and the transformed Eulerian mean (TEM) calculation. Above $25 \mathrm{~km}$ the dry anomalies in May and the moist anomalies in November compare well with the corresponding features in Plates $1 \mathrm{a}$ and $1 \mathrm{~b}$, consistent with the expectation that SAGE II should see the tape signal re-emerging above the aerosol layer.

We also show (Plate $1 \mathrm{~d}$ ) results from the 2-D trajectory calculation described by Mote et al. [1995] and briefly summarized here. Monthly mean TEM stream functions are calculated for 1992 and 1993 as described by Rosenlof [1995]. The method uses radiative heating rates based on observed temperatures, ozone, water vapor, and methane and on monthly averaged climatological values for other radiatively active trace species. These monthly stream function estimates are interpolated to daily values, which are used to run 2-D back trajectories to the $100-\mathrm{hPa}$ surface. Trajectory endpoints were spaced on a nonuniform vertical grid about $1 \mathrm{~km}$ apart (whose levels are those used in the radiative calculation; note tick marks on the ordinate) and $2^{\circ}$ apart in latitude, from $12^{\circ} \mathrm{S}$ to $12^{\circ} \mathrm{N}$. When a trajectory crosses $100 \mathrm{hPa}$, a mixing ratio is assigned to it using the saturation mixing ratio given by the minimum zonally varying temperature at the crossing latitude within a week of the crossing date, using 100-hPa temperatures from the UKMO. The minimum $100-\mathrm{hPa}$ temperature on the latitude circle was chosen in anticipation of the likelihood that the coldest tropopause regions, wherever they might occur, would be the entry points for water vapor into the stratosphere. The mixing ratio results thus obtained for 1992 and 1993 were then averaged to reduce interannual variablity, particularly that associated with the QBO.

The smooth picture of the time-varying tape signal calculated this way (Plate $1 \mathrm{~d}$ ) bears a strong resemblance to the satellite observations (Plates la to 1c). As was shown by Mote et al. [1995], MLS minima and maxima at 46 and $22 \mathrm{hPa}$ occur within a month or two of the minima and maxima diagnosed by the TEM 2-D trajectory calculation. The TEM calculation indicates transit times from the tropopause to 46,22 , and $10 \mathrm{hPa}$ of $8.5,13.5$, and 17 months, respectively, plus or minus about 2 months.

For a clearer picture of the vertical structure implied by Plate 1, we show in Figure 1 profiles of $q$ from HALOE and from the NOAA Lyman $\alpha$ hygrometer aboard the NASA ER-2 research aircraft in northern hemisphere autumn 1994. Data from both upward and downward paths of the ER-2 are shown, the scatter indicating the spatial variability at a pressure level. The HALOE profile represents an average of 7 tropical profiles in early November 1994. There are several differences between the aircraft and the satellite measurements that are consistent with the data characteristics. The HALOE instrument has approximately a 2 $\mathrm{km}$ resolution (the data points, at $0.2 \mathrm{~km}$ intervals, represent layers $2 \mathrm{~km}$ thick), while the NOAA hygrometer has a much finer vertical resolution. In addition, these altitudes are near the lower limit for $\operatorname{HALOE} q$, and some questionable data may be included in the average. HALOE water vapor tends to be generally lower than Lyman $\alpha$ water vapor, a bias that is not fully understood.

Both HALOE and the Lyman $\alpha$ hygrometer show a minimum at about $100 \mathrm{hPa}$, a maximum at about $70 \mathrm{hPa}$ in air that presumably left the tropopause a few months earlier, and a decrease above toward a secondary minimum in air that presumably left the tropopause the previous northern winter. Corresponding HALOE and ER-2 profiles in other seasons (not shown) have a vertical structure similarly consistent with the tape recorder hypothesis; for example, in July, $q$ values 

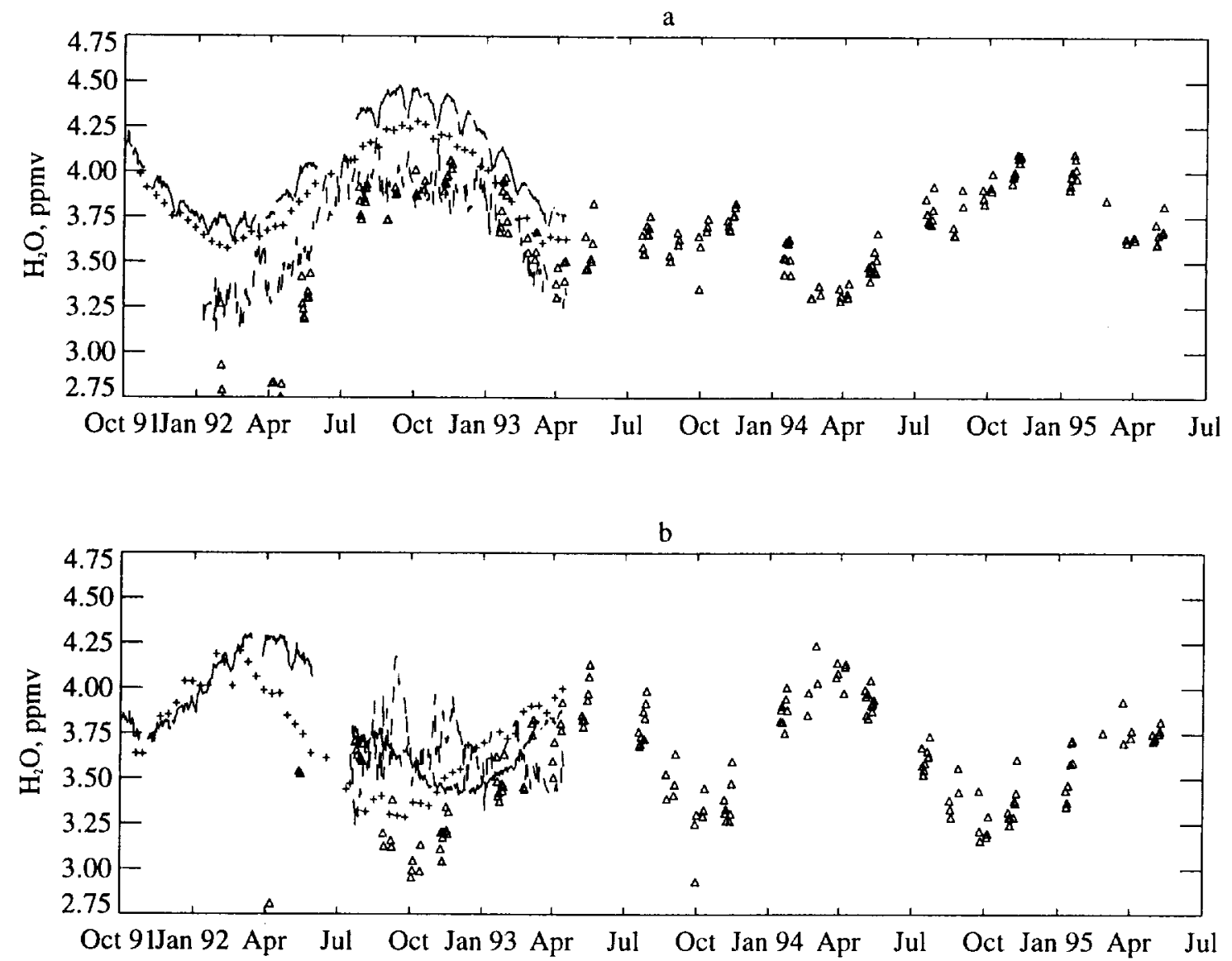

Figure 2. Comparison at (a) $22 \mathrm{hPa}$ and (b) $46 \mathrm{hPa}$ daily tropical $\left(10^{\circ} \mathrm{S}\right.$ to $\left.10^{\circ} \mathrm{N}\right) q$ measurements for version 3 MLS (solid curve), for new nonlinear MLS $(+)$, for HALOE $(\triangle)$, and for CLAES (dashed curve) during the period October 1991 to May 1995. Tick marks are at the beginnings of the months indicated.

at the tropopause are closer to 4 ppmv, the profile minimum occurs at about $65 \mathrm{hPa}$, and a maximum occurs at about $35 \mathrm{hPa}$. Further corroboration comes from balloon profiles (J. Ovarlez, personal communication, 1995; Ovarlez et al., submitted manuscript, 1995) in JanuaryFebruary 1994, when the profile maximum occurred at about $55 \mathrm{hPa}$. Weinstock et al. [1995] compared aircraft profiles taken in different months by using a temporally constant diabatic vertical velocity to "rewind the tape" to the previous January 1 , as we would say it in terms of the tape-recorder analogy. The results from both these studies corroborate the tape-recorder hypothesis.

In Figure 2 we compare daily mean tropical measurements of $q$ by MLS, HALOE, and CLAES, at two lower stratospheric levels for nearly 4 years after the launch of UARS. We show both the standard version 3 for MLS, the solid curves, and the results of the new, nonlinear retrieval, the plus symbols. For the period when all three instruments were operating, their annual variations are in moderately good agreement at $22 \mathrm{hPa}$ (Figure 2a). HALOE $q$ continues the pattern, with the lowest values in about April and the highest in about November, though with large interannual amplitude fluctuations. CLAES and MLS exhibit periodic irregularities associated with the yaw maneuver that UARS must perform. There are systematic differences among the instruments, however. Version 3 MLS water vapor is uniformly about $0.5 \mathrm{ppmv}$ higher than HALOE and CLAES; this is a known bias of MLS in the middle and upper stratosphere, and work is under way to correct it. The nonlinear retrieval produces values that are 0.1-0.2 ppmv lower than those from version 3 , but still higher than those from HALOE and CLAES. HALOE $q$ values are initially much lower than CLAES $q$ but converge with time toward CLAES $q$.

At $46 \mathrm{hPa}$ (Figure 2b), the instruments agree less well, especially in 1992. CLAES and HALOE may be significantly affected by the presence of volcanic aerosol, which decreases with time; CLAES data before July 1992 are omitted, and HALOE data before April 1992. The annual cycle in HALOE $q$ is somewhat clearer than at $22 \mathrm{hPa}$, with a minimum in about October or November and a maximum in about April or May. MLS and HALOE show similar annual variations (though both MLS retrievals are again higher), but MLS version 3 and the nonlinear retrieval have somewhat different phases of the annual cycle. We believe that this phase shift may be partly due to the influence of the annual cy- 


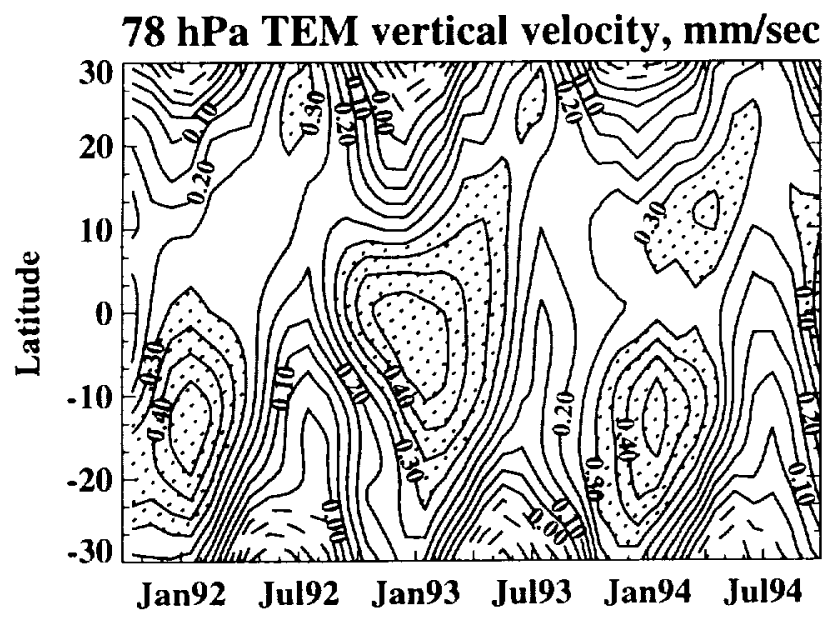

Figure 3. Seasonal variation of residual vertical velocity at $78 \mathrm{hPa}$ from October 1991 to October 1994 from the TEM calculation described in section 3. Contour interval is $0.05 \times 10^{-3} \mathrm{~m} \mathrm{~s}^{-1}$, negative contours are dashed, and values greater than $0.3 \times 10^{-3} \mathrm{~m} \mathrm{~s}^{-1}$ are shaded.

cle in the climatology used in the standard version 3 , which at $46 \mathrm{hPa}$ is in phase with the $100-\mathrm{hPa}$ annual cycle. Since the nonlinear retrieval not only seems to agree better with HALOE, but also relies less on climatology at this level than did the version 3 retrieval (in particular using a constant climatological profile rather than imposing an annual cycle), we are inclined to place more confidence in the results of the nonlinear retrieval.

\subsection{Variations in Ascent Rate}

We noted above that Plate $1 \mathrm{~b}$ implied a larger mean ascent rate during northern winter (about $0.4 \times 10^{-3} \mathrm{~m}$ $\mathrm{s}^{-1}$ ) than during the rest of the year (about $0.2 \times 10^{-3} \mathrm{~m}$ $\mathrm{s}^{-1}$ ). This is also clear in the original TEM 2-D trajectory calculation (Plate 1d). For a more detailed view, in Figure 3 we show the latitude-time variation of the vertical velocity at $78 \mathrm{hPa}$, just above the tropopause, as calculated by Rosenlof [1995]. The annual maximum (about $0.5 \times 10^{-3} \mathrm{~m} \mathrm{~s}^{-1}$ ) occurs south of the equator in December or January, and large ascent rates (greater than $0.3 \times 10^{-3} \mathrm{~m} \mathrm{~s}^{-1}$ ) also occur north of $10^{\circ} \mathrm{N}$ between March and July. There is also interannual variation of the latitude of the southern maximum, which in 19911992 and 1993-1994 lies further off the equator than in 1992-1993.

Carr et al. [1995] found (but did not show) an intriguing correlation between MLS $q$ at. $22 \mathrm{hPa}$ and an index of QBO-induced anomalies in vertical velocity. The index was defined as the zonal wind at $10 \mathrm{hPa}$ minus the zonal wind at $50 \mathrm{hPa}$. Successive minima in $q$ at both 22 and $46 \mathrm{hPa}$ appear to be at least 14 months apart in the MLS record (see Figure 2), raising questions about the relative importance of the QBO and the tropopause annual cycle in determining lower stratospheric $q$ values. In order to clarify the role of the QBO we used a two-dimensional model, which we now describe.
The "THIN AIR" model is described by Kinnersley $[1995,1996]$ and is an improved version of that described by Kinnersley and Harwood [1993]. Its improvements lie chiefly in the addition of three mutually interarting planetary-scale (zonal wavenumber 1-3) Rossby waves, whose breaking is parameterized and which are used to calculate consistently the Rossby wave drag on the zonal wind (important for the wave-driven pumping of the global circulation) and to parameterize the Rossby-wave-induced flux of trace gases. The wavebreaking parameterization is similar but not identical to that of Garcia [1991]. The model produces realistic zonal winds, temperatures, semiannual oscillation, annual cycles, and Rossby wave amplitudes [Kinnersley, 1996]. The parameterized QBO, with a period of almost exactly 2 years, is driven by the wave drag due to a thermally and frictionally damped Kelvin wave with a phase velocity of $20 \mathrm{~m} \mathrm{~s}^{-1}$, and an "anti-Kelvin wave" with a phase speed of $-20 \mathrm{~m} \mathrm{~s}^{-1}$ and the same dispersion relation and wave-induced momentum flux as the Kelvin wave [Kinnersley and Pawson, 1996]. The mode] is formulated with potential temperature as the vertical coordinate, except in the troposphere, where hybrid coordinates are used to avoid intersecting the ground. Levels are spaced at about $3.5 \mathrm{~km}$ from the ground to $100 \mathrm{~km}$. The latitudinal resolution is about $9.5^{\circ}$.

The model uses an upwind advection scheme, which has numerical diffusion that is unsatisfactory for handling strong gradients; we found that when we introduced an annually varying boundary condition for $q$ at the tropical tropopause, the annual variations traveled upward too quickly in comparison with the calculations of Mote et al. [1995], even though the vertical velocities were similar. We therefore represented the annual variations of $q$ by trajectories, which were calculated using modeled vertical velocities and ignoring horizontal motion except at the model tropopause. Parcels were assumed to leave the tropopause from the latitude box that had the largest upward velocity, thus accounting for the seasonal movement of upwelling $\left(9.5^{\circ} \mathrm{S}\right.$ in January to $9.5^{\circ} \mathrm{N}$ in July; compare with Figure 3$)$, but after leaving this box they were assumed to remain over the equator and so were advected with the equatorial vertical velocity. Each parcel was assigned an annually varying initial value of $q$ with a minimum of 2 ppmv in February and a maximum of 4 ppmv in August, and the values of $q$ were relaxed to 3 ppmv with an $c$-folding time of 200 days to represent the attenuation of the annual cycle with height. It should be noted that the attenuation time in the real tropics appears to be longer; see section 3.3 .

The only source of interannual variability in the THIN AIR model is the QBO; and in a 7-year run we found a]ternate years to be nearly identical. Figure 4 it shows 4 years of results from the THIN AIR trajectory calculation. The vertical derivative of zonal mean zonal wind is also shown (dark contours) and will be discussed below. Note that the ascent rate of the water vapor contours varies from year to year depending on the sign of the wind shear, an effect that is most pronounced between 
a

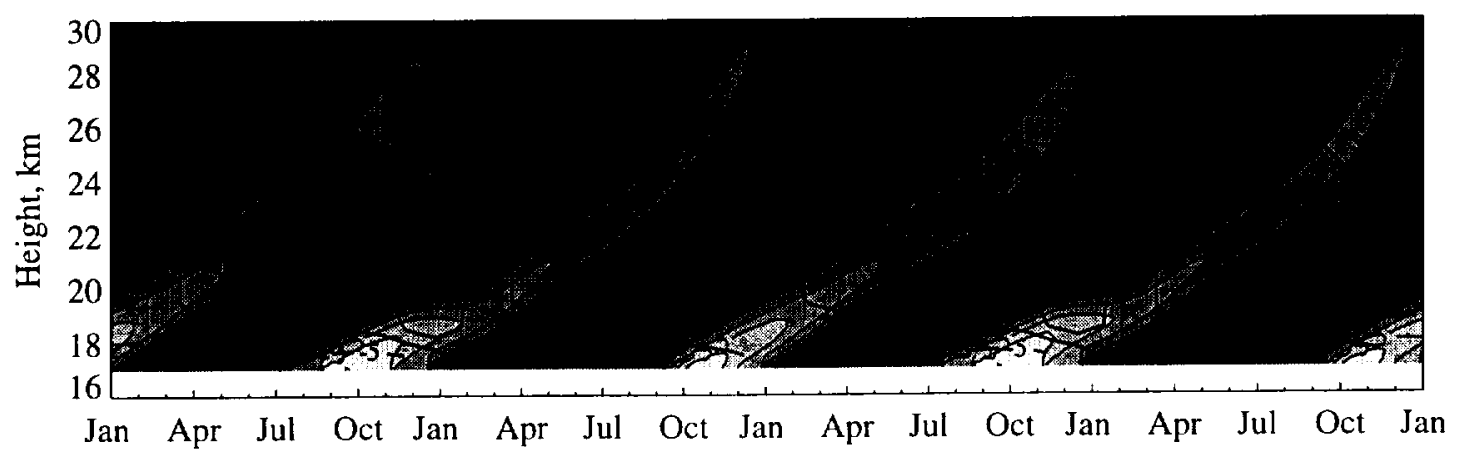

b

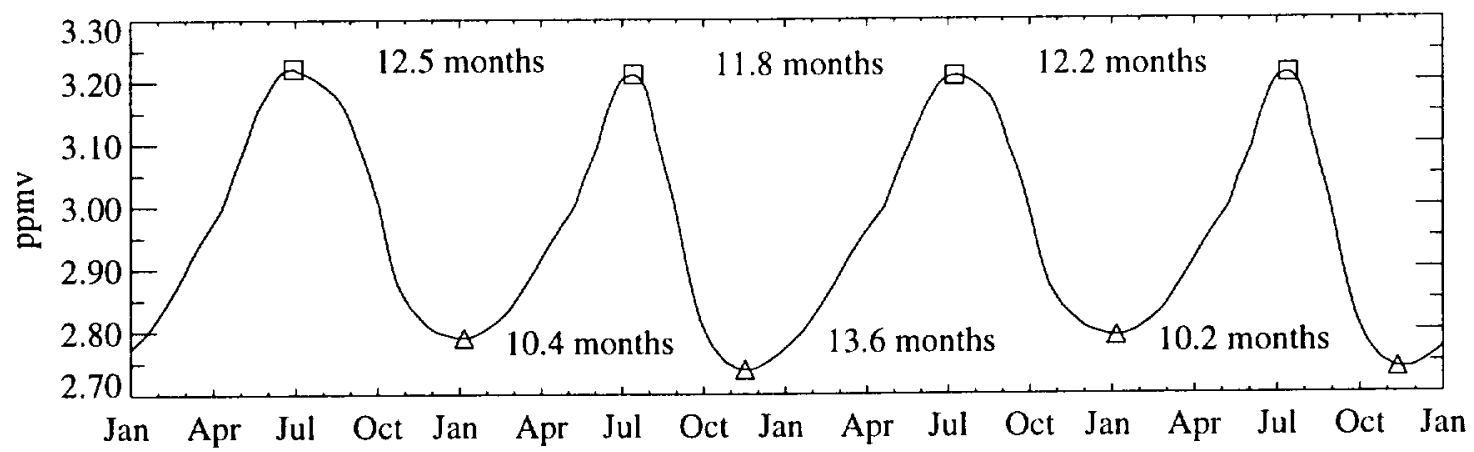

Figure 4. (a) THIN AIR 2-D model equatorial parcel water vapor mixing ratio (light shading, moist; dark shading, dry; contour interval, $0.2 \mathrm{ppmv}$ ). Also plotted is the vertical shear of the zonal mean zonal wind (dashed contours, negative shear; (solid contours, zero or positive shear; contour interval, $5 \mathrm{~m} \mathrm{~s}^{-1} \mathrm{~km}^{-1}$ ). (b) Time series of parcel water vapor at $22.5 \mathrm{~km}$ (about 40 $\mathrm{hPa}$ ) from the THIN AIR model. Intervals between successive minima and maxima (labelled by triangles and squares, respectively) are indicated.

18 and $22 \mathrm{~km}$. Figure $4 \mathrm{~b}$ shows a slice through Figure $4 \mathrm{a}$, a time series of mixing ratio of parcels passing the $22.5 \mathrm{~km}$ (about $40 \mathrm{hPa}$ ) level. The times between successive minima or successive maxima are labelled; the minima are from 10.2 to 13.6 months apart depending on the phase of the model QBO.

Easterly or negative vertical shear of zonal wind (dashed contours) implies lower equatorial temperatures and enhanced ascent, while westerly or positive vertical shear implies higher temperatures and reduced ascent. These effects are clear in Figure 4a: regions of positive shear show slower ascent (flatter contours) than regions of negative shear.

In the real atmosphere from November 1991 to about May 1992, negative shear of zonal wind prevailed between 20 and $100 \mathrm{hPa}$ [Swinbank and $O^{\prime}$ Neill, 1994], implying earlier arrival of minima and maxima in $q$ at a given pressure level. As the $\mathrm{QBO}$ casterlies descended, giving way to westerlies, the $\mathrm{QBO}$-induced vertical motion caused reduced ascent rates below $22 \mathrm{hPa}$, implying later arrival of minima and maxima in $q$ at $22 \mathrm{hPa}$. A 1month-early arrival of the 1991 100-hPa minimum, due at $22 \mathrm{hPa}$ in March 1992, and a 1-month-late arrival of the $1992100-\mathrm{hPa}$ minimum, due at $22 \mathrm{hPa}$ in $\mathrm{March}$ 1993, explain the 14-month interval between minima in the left half of Figure $2 \mathrm{a}$ as indicated by MLS and CLAES. 'The model QBO (Figure 4) produces a very similar interval (13.6 months) and shows that shorter intervals should alternate with longer intervals to produce a long-term mean interval of about 12 months. The timing is harder to deduce from the longer $\mathrm{HAJ}, \mathrm{OE}$ record because of its poorer time resolution, but the $1993100-\mathrm{l}_{\mathrm{l}} \mathrm{Pa}$ minimum seems to arrive at $22 \mathrm{hPa}$ in about March 1994. The shapes of HALOE vertical profiles (not shown) differ from year to year in a manner that is consistent with stretching or compressing of the tape signal by the QBO. Note that because the TEM calculation was based on an average of 1992 and 1993 data, there is no interannual variability in Plate $1 \mathrm{~d}$ as there is in Figure 4a.

\subsection{Variations in Tropopause Temperature}

To check the tape recorder hypothesis quantitatively, we would have to find a way to relate the observed tape signal to the mixing ratio of air entering the stratosphere. In formulating our TEM 2-D trajectory calculation, we assumed that the effective entry mixing ratio $q_{\mathrm{E}}$ could be found by tracing tropical air back to the latitude at which it crossed the 100-hPa surface and finding the saturation mixing ratio $q_{\mathrm{s}}$ not at the mean, but at the lowest UKMO 100-hPa temperature on the corresponding latitude circle. We now examine severa] facets of this calculation, and the detailed assumptions involved, in an attempt to explain the amplitude dis- 
crepancy mentioned in section 1:

(1) the selection of an appropriate area of the tropics for the air to enter the stratosphere,

(2) the difference between $100-\mathrm{hPa} q_{\mathrm{s}}$ and profile minimum $q_{\mathrm{s}}$

(3) the difference between gridded and actual temperatures,

(4) relevant aspects of the UKMO data assimilation and interpolation to UARS levels,

(5) large-scale 3-D motions not accounted for by the TEM calculation

(6) small-scale, unresolved 3-D motions near the tropopause, including the possibility of "hyperventilation." 'Ihese points are discussed in order in the following subsections.

3.2.1. Selection of an appropriate area of the tropics for the air to enter. It is generally accepted that tropical area-averaged tropopause temperatures are too high to explain observed $q$ values [Newell and Gould-Stewart, 1981; Holton, 1984]. We must therefore choose our $q_{\mathrm{s}}$ values from only some portion of the tropics where temperatures are below the mean. The first and simplest approach would be to use the lowest $100-\mathrm{hPa}$ temperature anywhere in the tropics. But one might expect this to underestimate $q_{\mathrm{E}}$ severely, and in any case it seems unrealistic in that it implies an assumption that all air enters at one grid point. A second approach would be to assume that air enters the stratosphere only at times and locations whose saturation mixing ratio $q_{s}$ falls below some upper limit; this is the "stratospheric fountain" hypothesis of Newell and Gould-Stewart [1981]. A third approach is the one we chose: to rely on the TEM calculation to select (and apply appropriate weights to) the latitudes where air in the tropics first crossed the 100-hPa surface, and to use the minimum $q_{\mathrm{s}}$ on each latitude circle. This approach too has limitations, and might also be expected to underestimate $q_{\mathrm{E}}$; but we find that the situation is not so simple.

To see what result might be expected from the third approach, we consider regional averages of $q_{\mathrm{s}}$. Atticks and Robinson [1983], using radiosonde data from 1979 , presented statistics of tropopause and $100-h_{\mathrm{Pa}} q_{\mathrm{s}}$ in different periods and regions in the tropics. They showed that very low tropopause values of $q_{\mathrm{s}}$, with extremes below $1.6 \mathrm{ppmv}$, were most common during northern winter in the region $10^{\circ} \mathrm{S}$ to $10^{\circ} \mathrm{N}, 90^{\circ} \mathrm{E}$ to $150^{\circ} \mathrm{W}$ (approximately the "fountain" region of Newell and GouldStewart [1981]). For this whole region and for the period January 25 to February 12, 1979, we find, from Atticks and Robinson's tables, a regional average tropopause $q_{\mathrm{s}}$ of $3.5 \mathrm{ppmv}$. The TEM 2-D trajectory calculation yields a minimum $q_{\mathrm{F}}$ of 2.9 ppmv, lying between the regional average $3.5 \mathrm{ppmv}$ and the extreme values below 1.6 ppmv and remarkably close, moreover, to the minimum $q$ values observed by HALOE at $46 \mathrm{hPa}$, around 3.0 ppmv (Figure 2b). But in northern summer the situation is completely different. For the period July $5-22,1979$, the average $q_{\mathrm{s}}$ for the same region is 6.1 ppmv. The TEM calculation yields a maximum $q_{\mathrm{E}}$ of
7.5 ppmv. Both values are well above the maximum observed at $46 \mathrm{hPa}$, around $4.2 \mathrm{ppmv}$ (Figure 2b). It appears that the TEM calculation is grossly overestimating, not underestimating, $q_{\mathrm{E}}$ in northern summer.

In addition, Atticks and Robinson's tables allow us to calculate the regional average tropopause $q_{\mathrm{s}}$ for July 522 in the Asian monsoon region $\left(10^{\circ}-25^{\circ} \mathrm{N}, 70-110^{\circ} \mathrm{E}\right)$. This regional average is found to be $4.7 \mathrm{ppmv}$, closer to the $46 \mathrm{hPa}$ maximum of about $4.2 \mathrm{ppmv}$. Now, in the TEM calculation the 2-D back trajectories from the middle stratosphere between $10^{\circ} \mathrm{S}$ and $10^{\circ} \mathrm{N}$ generally cross the tropopause in a narrower latitude band, usually south of $12^{\circ} \mathrm{N}$. In the TEM zonal mean picture, taken literally, air from the colder tropopause over the Asian monsoon region passes upward, northward, then downward again, such that it never reaches the middle stratosphere (see the plot of residual mean stream function in July presented by Rosenlof [1995]) and thus does not influence the TEM calculation of $q_{\mathbf{E}}$. If this were truly what happens to air parcels (a point to which we return in sections 3.2 .5 and 3.2 .6 ), then the region of the monsoon would have no influence on middlestratospheric trace constituents, including water vapor, between $12^{\circ} \mathrm{S}$ and $12^{\circ} \mathrm{N}$.

However, even if the TEM trajectories were replaced by more realistic, 3-D trajectories, there would still be another problem. Suppose for instance that all the air at $46 \mathrm{hPa}$ that passed through the tropical tropopause in northern summer came from the Asian monsoon region. The $100-\mathrm{hPa}$ UKMO temperatures in that region would be inconsistent with the notion that the air was dried to the saturation mixing ratio $q_{\mathrm{s}}$ there. The $100-\mathrm{h} \mathrm{Pa}$ temperatures for which $q_{\mathrm{s}}$ equals the lowest (3.0 ppmv) and highest (4.2 ppmv) reliable values of $q$ observed at $46 \mathrm{hPa}$ by UARS instruments (Figure 2b) are $189.6 \mathrm{~K}$ and $191.6 \mathrm{~K}$, respectively. These values are rather rare in UKMO $100-\mathrm{hPa}$ temperature data. This can be seen from Figure 5. Figure 5 a shows time series of the average and minimum UKMO $100-\mathrm{hPa}$ temperatures between $30^{\circ} \mathrm{S}$ and $30^{\circ} \mathrm{N}$ (note the horizontal line showing $189.6 \mathrm{~K}$ ). Figure $5 \mathrm{~b}$ shows the fraction of the area of the $30^{\circ} \mathrm{S}$ to $30^{\circ} \mathrm{N}$ region with temperatures less than $191.6 \mathrm{~K}$. Assuming that the driest air at 46 $\mathrm{hPa}$ entered the stratosphere in northern winter, only a few grid points could explain a value of 3.0 ppmv, let alone lower values. (In fact both HALOE and the MLS nonlinear retrieval indicate much lower values than this at levels between 100 and $46 \mathrm{hPa}$, though the significance is unclear because the data there have larger error bars.) Also, although some grid points (generally fewer than $5 \%$ of them) are cold enough in northern winter to explain a value of $4.2 \mathrm{ppmv}$, none are cold enough in northern summer, when the minimum $100-\mathrm{hPa} q_{\mathrm{s}}$ exceeds 7 ppmv. It is clear from Figure 5, then, that any air entering the stratosphere in northern summer and dried to saturation (at the UKMO 100-hPa temperatures) would be much moister than observed.

Is it possible that air simply does not enter the stratosphere when $q_{\mathrm{s}}$ is too high, that is, for several months in northern summer? On the contrary, the $\mathrm{CO}_{2}$ data of 
a

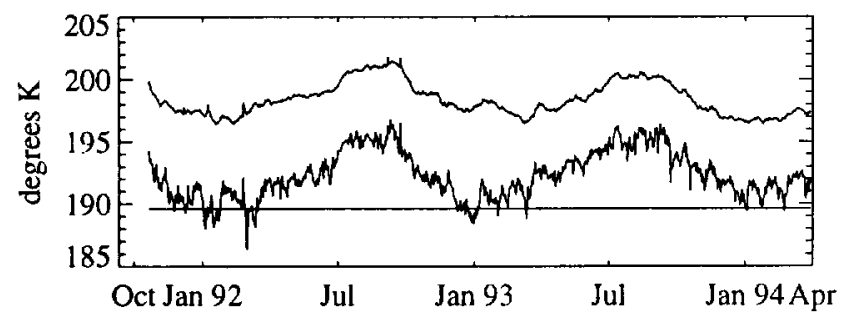

b

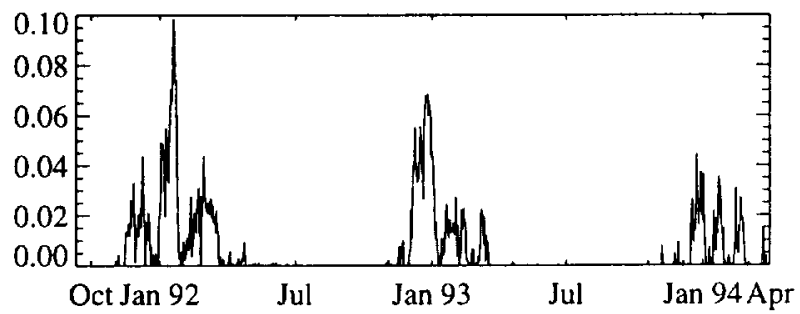

Figure 5. Statistics from 100-hPa UKMO assimilated temperature data for October 1991 to April 1994, for the area between $30^{\circ} \mathrm{S}$ and $30^{\circ} \mathrm{N}$. (a) Area average temperature (top curve) and minimum temperature (bottom curve); horizontal line indicates $189.6 \mathrm{~K}$. (b) Fraction of the area covered by temperatures less than 191.6 $\mathrm{K}$. The values $189.6 \mathrm{~K}$ and $191.6 \mathrm{~K}$ are the temperatures at which $q_{\mathrm{s}}$ at $100 \mathrm{hPa}$ equals the lowest and highest reliable $q$ values in Figure 2, taken respectively as 3.0 ppmv and 4.2 ppmv.

Boering et al. [1995] suggest continuous entry of air to the stratosphere, a view consistent with the satellite observations of $q$ (Plate 1). Furthermore, the TEM calculation has nonzero vertical velocity at $100 \mathrm{hPa}$ throughout the year, as also expected for robust dynamical reasons [e.g., Holton et al., 1995, Haynes et al., 1996]. It therefore seems more sensible to allow the TEM calculation, as far as it is able, to select the appropriate region, rather than to use only $100-\mathrm{hPa}$ temperatures that fall below a certain limit, which in any case would not make sense in northern summer because then the limit is not attained at all. Our choice of the minimum $q_{\mathrm{s}}$ on each latitude circle, though apparently somewhat arbitrary, did succeed remarkably well in compensating the errors associated with points 2,3 and 4 in northern winter though not in northern summer. One factor to which the northern summer discrepancy points very strongly is the difference between $100-\mathrm{hPa} q_{\mathrm{s}}$ and profile minimum $q_{\mathrm{s}}$. This is considered in the next subsection.

First, however, we should ask how important interannual variability might be. Is it reasonable to compare area-averaged $q_{\mathrm{s}}$ values for 1979 with data from different years, in particular the $q_{\mathrm{E}}$ values diagnosed from 1992-1993 100-hPa temperatures? Frederick and Douglass [1983] showed annual mean 100-hPa temperatures for 1972-1979 for several tropical stations. For most such stations, especially those with lowest mean temperatures, interannual variations were of the order of $1 \mathrm{~K}$ or less. They also stated [Frederick and Douglass, 1983, p. 1399] that "most of the variance [about the long-term mean] is in the annual cycle." Our own inspection of $100-\mathrm{hPa}$ analyses from the European Centre for Medium-Range Weather Forecasts (ECMWF), for 1986-1989 suggests that some interannual variation of $100-\mathrm{hPa}$ temperatures in the western Pacific results merely from the movement of the temperature contours, which has little effect on the area-averaged $q_{\mathrm{s}}$. Figure 5 also suggests that interannual variations are smaller than annual and intra-annual variations.

3.2.2. Difference between 100-hPa $q_{\mathrm{s}}$ and profile minimum $q_{\mathrm{s}}$. Frederick and Douglass [1983] have noted that if the tropopause pressure $p_{\mathrm{t}}$ is less than 100 $\mathrm{h} P a$, then replacing tropopause temperature $T_{\mathrm{t}}$ by $100-$ hPa temperature $T_{100}$ would overestimate profile minimum $q_{\mathrm{s}}$, because the higher temperature gives higher $q_{\mathrm{s}}$, whereas replacing $p_{\mathrm{t}}$ by $100 \mathrm{hPa}$ would underestimate $q_{\mathbf{s}}$, because $q_{\mathbf{s}} \propto p^{-1}$ where $p$ is air pressure. It happens that the two effects approximately cancel when $p_{\mathrm{t}}<100 \mathrm{hPa}$. Conversely, the two effects reinforce when the $p_{\mathrm{t}}>100 \mathrm{hPa}$, as is common in northern summer, giving an overestimate of minimum $q_{\mathrm{s}}$. Reid and Gage [1981] showed that, over a large area of the tropics, tropopause heights are indeed lowest in northern summer and highest in northern winter. The question, then, is: could the seasonal migration of the tropopause across the $100-\mathrm{hPa}$ surface explain the amplitude discrepancy in the tape signal?

We look first at some relevant observational information for the equatorial western Pacific, yielding time series of the two types of $q_{\mathrm{s}}$ estimate just discussed, say $q_{\mathrm{s} 100}$ and $q_{\mathrm{st}}, q_{\mathrm{s} 100}$ being the estimate from $T_{100}$ and $q_{\mathrm{st}}$ being the estimate from $T_{\mathrm{t}}$ and $p_{\mathrm{t}}$. Time series of monthly mean $T_{100}, T_{\mathrm{t}}$, and $p_{\mathrm{t}}$ derived from radiosonde profiles were kindly provided by G. Reid for the island of Koror in the equatorial western Pacific $\left(7^{\circ} \mathrm{N}, 134^{\circ} \mathrm{E}\right)$, for the period 1965-1981. Figure 6a compares the resulting $q_{\mathrm{s} 100}$ and $q_{\mathrm{st}}$, and Figure $6 \mathrm{~b}$ shows the difference $\left(q_{\mathrm{s} 100}-q_{\mathrm{st}}\right)$. From November to May the tropopause is between 95 and $98 \mathrm{hPa}$ and the mean thermal structure is such that $q_{\mathrm{s} 100} \approx q_{\mathrm{st}}$. This illustrates the approximate cancellation already mentioned. From June to September, however, the difference between $q_{\mathrm{s} 100}$ and $q_{\mathrm{st}}$ is much larger, close to 2 ppmv. Atticks and Robinson [1983] display an area mean vertical profile of temperature for the $150^{\circ} \mathrm{E}$ to $150^{\circ} \mathrm{W}$ sector, just east of Koror, and there too $q_{\mathrm{s} 100} \approx q_{\mathrm{st}}$ in northern winter but not in northern summer.

It is possible of course that the use of time series of monthly means may obscure some relevant information. Also, as Frederick and Douglass noted, the $p$ dependence of $q_{\mathrm{s}}$ implies that there is an additional difference, which is usually small, between the $q_{\mathrm{st}}$ defined above and the true profile minimum value of $q_{\mathrm{s}}$.

Figure 6 goes some way $(2 \mathrm{ppmv})$ toward explaining the amplitude discrepancy in the TEM 2-D trajectory calculation, but are such differences between $q_{\mathrm{s} 100}$ and $q_{\mathrm{st}}$ found throughout the tropics? In northern winter, the lowest $T_{\mathrm{t}}$ values usually occur near Koror, but in northern summer they occur over the Asian monsoon region, and a number of studies show 

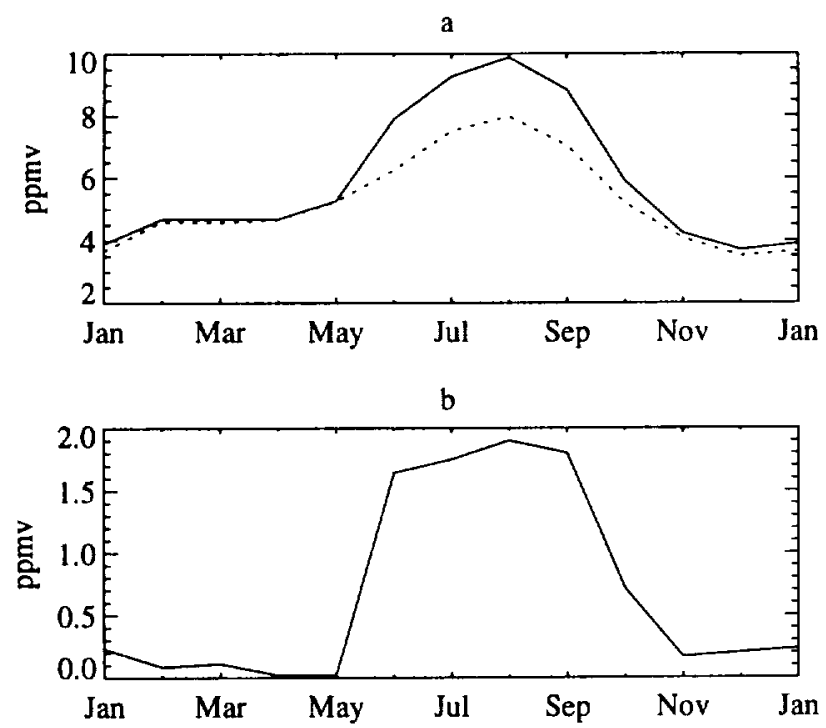

Figure 6. Seasonal variation of the error from using 100 -hPa temperatures to estimate minimum $q_{\mathbf{s}}$, illustrated by monthly mean radiosonde data from Koror $\left(7^{\circ} \mathrm{N}, 134^{\circ} \mathrm{E}\right)$ for $1965-1981$. (a) Solid curve shows the estimate $q_{\mathrm{s}_{100}}$ of minimum $q_{\mathrm{s}}$, computed from $100-\mathrm{hPa}$ temperature and pressure; dotted curve shows the estimate $q_{\mathrm{st}}$ from tropopause temperature and pressure. (b) Curve shows the difference $\left(q_{\mathrm{s} 100}-q_{\mathrm{st}}\right)$ on an expanded scale. Data by courtesy of G. Reid.

that $p_{\mathrm{t}}<100 \mathrm{hPa}$ there. Atticks and Robinson [1983] binned profile-minimum temperature $T_{\min }$ and the corresponding pressure $p_{\min }$ for hundreds of radiosonde ascents. For the region $10^{\circ} \mathrm{S}$ to $10^{\circ} \mathrm{N}, 150^{\circ} \mathrm{E}$ to $150^{\circ} \mathrm{W}$ in northern winter, the bin with the most data points had $p_{\min }=92.5 \mathrm{hPa}$, and for the region $10^{\circ}-25^{\circ} \mathrm{N}$, $70^{\circ}-110^{\circ} \mathrm{E}$ in northern summer, the bin with the most points had $p_{\min }=97.5 \mathrm{hPa}$. Also, Krishna Murthy et al. [1986] showed that over Delhi (but not southern India), the monthly mean $p_{\mathrm{t}}$ was less than $100 \mathrm{hPa}$ in summer. Finally, an analysis of ECMWF data (E. Highwood, personal communication, 1995), which used lapse rates to find the tropopause between vertical grid points, likewise showed $p_{\mathrm{t}}$ less than $100 \mathrm{hPa}$ over much of northern India and the Bay of Bengal in northern summer. These studies imply that, in the Asian monsoon region during northern summer, $q_{\mathrm{s}_{100}}$ could be a reasonable proxy for $q_{\mathrm{st}}$ if gridded $T_{100}$ values are accurate enough. The 2 ppmv difference during northern summer (Figure $6 \mathrm{~b}$ ) probably does not apply to the region of lowest $T_{t}$ (the Asian monsoon) then. There is, however, an unexplained discrepancy between the $q_{\mathrm{s}}$ values ( $>7 \mathrm{ppmv}$ ) diagnosed from UKMO minimum $100 \mathrm{hPa}$ temperatures (Figure 5a) in northern summer and area averaged $q_{\mathrm{s}}$ values (4.7 ppmv) derived from the tables of Atticks and Robinson [1983].

3.2.3. Difference between gridded and actual temperatures.

The caveat about gridded $T_{100}$ being accurate enough is crucial. For instance, even over the Asian monsoon region, the UKMO gridded $T_{100}$ values are far too high, as mentioned earlier, to account for observed $q$ values at $46 \mathrm{hPa}$ : the gridded values gave $q_{\mathrm{s}}$ exceeding $7 \mathrm{ppmv}$ as compared with the $46 \mathrm{hPa}$ maximum of about 4.2 ppmv. One question is whether horizontal grid resolution limitations are important, especially as there is ample reason to believe that cumulonimbus convection plays an important role, locally, in the process of transferring mass to the stratosphere [e.g., Kelly et al., 1993; Kritz et al., 1993]. Processes at and near the tops of penetrating convective clouds are probably an essential component especially as regards estimating $q_{\mathrm{E}}[\mathrm{e} . \mathrm{g}$. , Danielsen, 1982]; but the extremely low temperatures involved are both too transient and too fine in scale to be well represented even in radiosonde data, let alone in gridded data after assimilation.

Despite these limitations we may try to see what radiosonde data can tell us about the frequency and seasonal distribution of very low temperatures and $q_{\mathrm{s}}$ values, and try to relate these to our grid-based estimates of $q_{\mathrm{E}}$. The study by Atticks and Robinson [1983] is again helpful. They plotted $T_{\min }$ against $p_{\min }$ for each of hundreds of radiosonde profiles. For the region $10^{\circ} \mathrm{S}$ to $10^{\circ} \mathrm{N}, 150^{\circ} \mathrm{E}$ to $150^{\circ} \mathrm{W}$ over a 20 -day period in northern winter, dozens of profiles had $T_{\min }$ values less than $186 \mathrm{~K}$ (the lowest UKMO $T_{100}$ value in Figure 5), and at $p_{\min }$ values ranging from 80 to $110 \mathrm{hPa}$, implying $q_{s_{\min }}$ approaching $1 \mathrm{ppmv}$. They noted that none of these radiosonde profiles coincided with active convection, so it is possible that convective events would briefly produce even lower $q_{\mathrm{s}_{\min }}$ values. It seems plausible therefore that the synoptic scale of the gridded data is insufficient to resolve the smaller scales, where very low temperatures associated with convection are probably of key importance to $q_{\mathrm{E}}$. The implication is that, for the purpose of estimating $q_{\mathrm{E}}$, a warm bias is inherent in the gridding process. In our TEM 2-D calculation we sought to compensate, in effect, for the warm bias by choosing the lowest available temperature on each latitude circle.

3.2.4. Relevant aspects of the UKMO data assimilation and interpolation to UARS levels. As the preceding sections suggest, the vertical and horizontal resolution of assimilated data may sharply limit our ability to estimate $q_{\mathrm{E}}$. For the TEM 2-D calculation we used UKMO data because they were conveniently available as part of the UARS correlative data base and they were on a regular spatial grid, simplifying the calculation of a weighted-average $q_{\mathrm{s}}$ as our estimate of $q_{\mathrm{E}}$. In the statistics produced as part of the UKMO data assimilation process, the region between $30^{\circ} \mathrm{S}$ and $30^{\circ} \mathrm{N}$ and between 50 and $100 \mathrm{hPa}$ has one of the largest absolute means $(-0.5 \mathrm{~K})$ of the quantity defined as observed minus analyzed temperature ( $R$. Swinbank, personal communication, 1994). This is an additional warm bias.

Another problem is that $T_{100}$ values have to be found by interpolating between the 89 and $112 \mathrm{hPa}$ model levels. Although the interpolation is nonlinear, it is likely to overestimate $T_{\min }$. The combination of an 
assimilation bias and an interpolation bias, adding to the horizontal-resolution bias discussed in section 3.2.3, could well be significant: if the minimum temperature curve in Figure 5a were shifted down by, say, a degree, the fraction of grid points cold enough to explain observed mixing ratios would increase markedly.

The bias in UKMO tropical lower stratospheric temperatures can have an effect on the TEM stream function itself. Uncorrected, it would yield vertical velocities that are too weak. But because we correct for global mass balance, we can reasonably assume that the worst such errors have been taken out, though there remain other complications [e.g., Shine, 1989], and it is difficult to be sure just what the net effect would be.

3.2.5. Large-scale 3-D motion not accounted for by the TEM 2-D calculation. Our approach to calculating $q_{\mathrm{E}}$, by backward trajectories to the tropopause is limited by the accuracy of the TEM calculation in the lower stratosphere. Radiative errors, though estimated to be small, arise from many sources besides the important temperature errors already discussed. Outside the radiation scheme itself there is the simplified climatological treatment of clouds, and the errors in measurements of ozone and water vapor in the lower stratosphere. It seems plausible that such errors could contribute to errors in the source latitude of stratospheric air. But a still more serious error arises from zonal averaging. Stratospheric air at a given latitude could very well trace its origins to a far wider range of latitudes than the TEM 2-D calculation would indicate; and this could be especially serious in northern summer, as already noted.

One of us (K.H.R.) conducted a preliminary study of the impact of such errors by running 3-D backward trajectories from $55 \mathrm{hPa}$ using observed (UKMO) winds, starting in January and July and running the trajectories back for 6 months. These results show that air does indeed come from a wider range of latitudes than the TEM calculation would indicate, and furthermore that it crossed the tropopause at a range of times. Many of the parcels that started in January crossed the tropopause in the Asian monsoon region during the previous summer, but many also crossed the tropopause in September or October. Even more came from the extratropical stratosphere.

The fact that the (mass balance corrected) TEM calculation nevertheless produces remarkably good phase agreement with observed $q$ (Plate 1; Mote et al. [1995]) argues strongly for corresponding accuracy of the TEM vertical velocities. Indeed, Plate 1 can be looked on as a stringent independent check on such accuracy. What the TEM 2-D calculation cannot adequately represent is all the detail in the highly disturbed layers just above the tropopause, hence statistics of pathways from the tropopause, hence $q_{\mathrm{E}}$ values.

3.2.6. Small-scale, unresolved 3-D motion near the tropopause, including the possibility of "hyperventilation." It is possible that gridded data misrepresents not only temperatures but also transport. For example, suppose that there exists a sub-grid-scale mechanism for selecting only the driest air to be taken up into the tropical middle stratosphere. One such inechanism that is physically possible, indeed arguably likely to operate for part of the time at least, is what might be called "hyperventilation" of the tropical lower stratosphere by the tallest cumulonimbus clouds. Hyperventilation means that the tallest clouds inject significantly more dry air into the tropical lower stratosphere than can be taken up into the middle stratosphere by the large-scale (extratropically controlled) advection. In a hyperventilated lower stratosphere, the excess mass injected has to be displaced back downward or sideways.

The possibility of hyperventilation arises from the possibility that the tail of the statistical distribution of tall cumulonimbus injection altitudes is associated with a strongly negative contribution to the subgrid-scale upward eddy flux of water vapor in the lower stratosphere, while not being sufficient to carve out a new tropopause at the same altitude. The eddy flux could behave in this way because the upward motion associated with tall cumulonimbus penetrations is likely to be strongly correlated with the lowest extreme $q$ values, i.e. with strongly negative $q^{\prime}$. The water vapor fluxes can thus behave differently from the eddy heat fluxes influencing tropopause formation.

A hyperventilated tropical lower stratosphere would evidently imply effective temperature and $q_{\mathrm{E}}$ values substantially less than those calculated from a largerscale view. The question of whether and when such hyperventilation is significant for $q_{\mathrm{E}}$ values in the real atmosphere needs, and deserves, further investigation. This will have to await detailed studies of cloud statistics, particularly the total mass flux from the tallest clouds into the stratosphere.

\subsection{Mixing}

The observed tape signal contains useful new information, difficult to obtain otherwise, about vertical mixing within the tropics and near-horizontal isentropic mixing into the tropics. This complements what is already known about mixing out from the tropics from, for instance, the studies of nuclear bomb test debris [Feely and Spar, 1960] and of water vapor [Mastenbrook and Oltmans, 1983; McCormick et al., 1993] and from diagnoses of transport using analyzed winds [Chen et al., 1994; Waugh, 1996]. These studies have indicated that near-horizontal isentropic transport out of the tropics is more rapid and effective in the lowest few kilometers of the stratosphere than at somewhat higher altitudes. The tape signal provides new information about this.

Mixing-in rates need not be closely comparable to mixing-out rates. The very existence of the tape signal reminds us that the tropical stratosphere is somewhat isolated from the surrounding extratropics [e.g., Trepte and Hitchman, 1992], to an extent that varies with altitude, and that this is presumably due to the existence, in the subtropics, of the kind of flexible, quasi-elastic "eddy transport barrier" that has been more exten- 
sively studied at the edges of the winter stratospheric polar vortices [e.g., Norton, 1994; Polvani et al., 1995; Holton et al., 1995]. Such eddy transport barriers depend on monotonic isentropic gradients of potential vorticity and horizontal shear acting together in a subtle way [Juckes and McIntyre, 1987], and there is no reason why mixing in to the tropical overworld need be as strong as mixing out to the extratropical overworld. Both tend to be inhibited by the eddy transport barrier, but not necessarily to the same extent because eddy details tend to be different (e.g., mixing out is associated with "erosion" of the barrier by midlatitude eddies). Therefore we cannot be certain that rates of mixing in will be the same as rates of mixing out. This makes estimates of mixing in, which are hard to obtain, especially interesting.

In this connection it is useful to note first that $\dot{H}=$ $2\left(\mathrm{CH}_{4}\right)+\left(\mathrm{H}_{2} \mathrm{O}\right)$ values in the extratropical overworld are nearly uniform at about the mean value of the tropical tape signal, about 6.5 ppmv. Note also that extratropical overworld fluctuations in $\hat{H}$ are probably due mostly to poleward erosion of tropical air and hence should be within the range of the tape signal. Larger departures from the mean value are found in the mesosphere and in the southern polar vortex, but these are unlikely to influence air that reaches the tropics [Mote, 1995]. Mixing in from the surrounding extratropics, therefore, is overwhelmingly likely to attenuate, not amplify, the tape signal.

Thus motivated, we have attempted to estimate the timescales for attenuation of the tape signal using HALOE $\hat{H}$ and MLS $q$ (which is better sampled, though more complicated to interpret because of methane oxidation). Two methods were used; the first was applied both to HALOE $H$ and to MLS $q$, and the second was applied only to HALOE $\hat{H}$. It turns out that the answers are nearly the same in each case. The first method is to calculate a peak-to-peak amplitude using the maximum and minimum for the entire data record at each altitude. The second, which can be applied only to HALOE because of its longer record, is to Fourier analyze 3 years of data and take the annual component. The amplitude calculated by the second method is smaller than that calculated by the first, but the fractional attenuation with height, i.e., the ratio of amplitudes at different heights, turns out to be nearly the same.

In view of the altitude dependence of mixing out already mentioned, which presumably indicates altitude dependence of the strength of the eddy transport barrier, we might expect the attenuation of the tape signal to show altitude dependence as well. In fact, we found that the UARS level at $46 \mathrm{hPa}$ roughly delimits two different regimes. Between 46 and $10 \mathrm{hPa}$ the peak-topeak amplitude of both HALOE $\hat{H}$ and MLS $q$ drops from 0.9 ppmv to 0.5 ppmv during the 9 months required for the journey. Assuming exponential decay, this implies an $e$-folding timescale $\tau$ of about 15-18 months. Between 100 and $46 \mathrm{hPa}$, however, the $e$ folding timescale $\tau$ is only about $7-9$ months. The slower degradation of the tape signal between 46 and $10 \mathrm{hPa}$ indicates less mixing in from the extratropics and/or less vertical mixing.

The $e$-folding attenuation times just estimated imply upper limits to vertical mixing rates in the tropical lower stratosphere. There is good reason to suppose that vertical mixing in the lower stratosphere can be represented in the ensemble mean by a true Fickian eddy diffusivity [Dewan, 1981]. There can be an additional (also Fickian) diffusivity from the quasi-random fluctuations in diabatic heating experienced by an air parcel. If $L$ is a typical vertical length scale, then Fickian diffusion implies a diffusive timescale $\tau_{\text {DIFF }} \sim$ $K_{z} / L^{2}$

Substitution of the observed values of $\tau$ into the relation $\tau_{\mathrm{DIFF}} \sim K_{z} / L^{2}$ gives upper limits on the total $K_{z}$ from all such effects. This is because such substitution amounts to assuming zero mixing in from the extratropics. Using the data from Plates $1 \mathrm{a}$ and $1 \mathrm{~b}$ to estimate $L$, we get vertical wavelengths $(=2 \pi \times L)$ of about $5-7 \mathrm{~km}$ between 100 and $46 \mathrm{hPa}$, and $8-12 \mathrm{~km}$ between 46 and $10 \mathrm{hPa}$. If there were no mixing-in, then we would have $\tau_{\text {DIFF }} \sim \tau \sim 7-9$ months between 100 and $46 \mathrm{hPa}$, and this gives a $K_{z}$ about $0.03-0.07$ $\mathrm{m}^{2} \mathrm{~s}^{-1}$ and a best estimate of about $0.04 \mathrm{~m}^{2} \mathrm{~s}^{-1}$. With $\tau_{\mathrm{DIFF}} \sim \tau \sim 15-18$ months between 46 and $10 \mathrm{hPa}$, this gives $K_{z}$ about $0.03-0.09 \mathrm{~m}^{2} \mathrm{~s}^{-1}$ and a best estimate of about $0.06 \mathrm{~m}^{2} \mathrm{~s}^{-1}$.

The independent studies of aircraft data by Avallone and Prather [1996], Boering et al. [1995], and K. Minschwaner et al (The bulk properties of isentropic mixing into the tropics in the lower stratosphere, submitted to Journal of Geophysical Research, 1995) indicate that some extratropical air is mixed into the tropics, with timescales similar to those we have just estimated. If so, the actual $K_{z}$ values must be even smaller. Even the $K_{z}$ values just deduced, which are upper limits on the order of magnitude of $K_{z}$, as just emphasized, seem distinctly smaller than values for $K_{z}$ like $0.2 \mathrm{~m}^{2} \mathrm{~s}^{-1}$ estimated from radar studies and from model studies like that of Dewan [1981] (also World Meteorological Organization (WMO) [1986, and references therein]).

A further reason for supposing that $K_{z}$ values are still smaller than the above estimates is the altitude dependence of the tape signal attenuation. The increase in attenuation times above the first few kilometers of the tropical stratosphere seems to mirror the upward decrease in poleward erosion rates found by Chen et al. [1994] and Waugh [1996] from the lower to the middle subtropical stratosphere. Even though, as was already mentioned, the eddy transport barrier need not inhibit mixing in to the same degree as mixing out, all the results under discussion seem consistent with hypothesizing a more effective subtropical eddy transport barrier in the middle stratosphere than in the first few kilometers of the overworld, i.e. in the first few kilometers above the $400 \mathrm{~K}$ isentrope. Long 3-D trajectory runs by one of us (K.H.R.) were used to trace the origin of tropical air at various altitudes, and these results, also, indicate that there is an altitude range in the tropics 
(within the overworld, between about 50 and $20 \mathrm{hPa}$ ) in which mixing in of midlatitude air is relatively slow.

\section{Conclusions}

Air transported upward by the extratropically driven global-scale mean circulation retains, for 18 months or more, a distinct "memory" of the tropical tropopause conditions it encountered. As was first shown by Mote et al. [1995], the timings of individual minima and maxima in tropical stratospheric water vapor $q$ at 46 and $22 \mathrm{hPa}$ are reasonably well represented by a 2-D transformed Eulerian mean (TEM) back trajectory calculation. This not only corroborates the tape recorder hypothesis but also validates the mass balance corrected radiative calculation in the lowest few kilometers of the tropical stratosphere, where heating rates are very small. The longest-running picture of the tape signal is provicied by HALOE $\hat{H}=2\left(\mathrm{CH}_{4}\right)+\left(\mathrm{H}_{2} \mathrm{O}\right.$ ) (Plate 1b), which also shows that, in the lowest few kilometers of th.? tropical stratosphere, ascent rates are smaller in northern summer (about $0.2 \times 10^{-3} \mathrm{~m} \mathrm{~s}^{-1}$ ) than in northern winter (about $0.4 \times 10^{-3} \mathrm{~m} \mathrm{~s}^{-1}$ ). These numbers provide a new independent check on the orders of magnitude of large-scale tropical stratospheric upwelling velocities previously estimated in other ways [e.g., Holton et al., 1995].

From Plate $1 b$ it is also clear that, most of the time, a tropical profile of $q$ would show two minima and two maxima between $100 \mathrm{hPa}$ and $10 \mathrm{hPa}$, like an upward extension of Figure 1. The upward advection of a seasonal minimum is a necessary part of this picture and thus seems to be the most likely explanation of the "elevated hygropause" [Kley et al., 1982; Kelly et al., 1993] than zonal advection from a contemporary distant source.

However, it is not clear in full detail how the initial marks on the tape are made, i.e., how the real atmosphere determines the effective "entry mixing ratio" $q_{\mathrm{E}}$ of air entering the tropical stratosphere. It became clear that establishing a quantitative link between $q_{\mathrm{E}}$ and assimilated temperatures near the tropopause would be an extremely formidable problem, beyond the scope of this study if not beyond present capabilities altogether. One would need accurate knowledge of many 3-D trajectories and of sub-grid-scale processes near the tropopause, including cloud-physics processes, as recalled below.

There is a large discrepancy between our $q_{\mathrm{E}}$ estimates from the TEM 2-D back trajectory calculation and the observed mixing ratios $q$ for air at higher altitudes such as $46 \mathrm{hPa}$, which probably entered the stratosphere in northern summer. We noted several possible reasons for this:

1. The TEM 2-D back trajectory calculation may not be able to trace trajectories back to the right locations near the tropopause, and almost certainly fails to do so in northern summer. Because the TEM calculation treats the tropics as zonally symmetric, it cannot describe zonally asymmetric circulations like the anticyclonic outflow from monsoon regions, which seem likely to be important to the determination of $q_{\mathrm{E}}$. In the tropical middle stratosphere the TEM calculation shows, probably unrealistically, no air originating from the Asian monsoon region during northern summer. In that region at that time, area-averaged tropopause $q_{\mathrm{s}}$ (from radiosonde data) is about $4.7 \mathrm{ppmv}$, close to the maximum $q$ observed at $46 \mathrm{hPa}$, about $4.2 \mathrm{ppmv}$. Compounding the problem with the trajectories is the problem discussed in section 3.2.2 (see also Figure 6), that tropopause $q_{\mathrm{s}}$, hence $q_{\mathrm{E}}$, can be grossly overestimated when tropopause pressures exceed $100 \mathrm{hPa}$, as may happen at tropopause locations indicated by unrealistic trajectories. This appears to account for a substantial part of the amplitude discrepancy, that is, the discrepancy in the 2-D estimates of $q_{\mathrm{E}}$.

2. The use of UKMO gridded 100-hPa temperatures to estimate $q_{\mathrm{E}}$ has shortcomings. In the data assimilation procedure, information about subgrid-scale temperature variations (which may be of critical importance to the question of how air enters the stratosphere) can be lost. Furthermore, the interpolation from model levels to $100 \mathrm{hPa}$ is almost certain to overestimate the model's tropopause temperature.

3. Air entering the stratosphere in northern summer is more likely to be modified by subsequent convection events, owing to the lower tropopause and slow mean ascent rate in the tropical lower stratosphere during that time of year. Such "hyperventilation" would replace moister air by drier air, like shuffling a horizontal deck of cards, leaving a drier signal on the tape than would be indicated by the synoptic-scale temperatures.

4. Moist air entering in northern summer may also be diluted by drier air from the extratropics, where mixing ratios are then lower. There is evidence from aircraft data that some air is mixed in from the extratropics between about 100 and $50 \mathrm{hPa}$, where Plates $1 \mathrm{a}$ and $1 \mathrm{~b}$ both show the greatest reduction in tape signal amplitude.

Establishing the relative importance of these factors would require considerable further work. Although a better estimate of the profile minimum $q_{\mathrm{s}}$ could be obtained by examining several hundred radiosonde ascents, as was done by Atticks and Robinson [1983], the improved vertical resolution would come at the expense of the horizontal grid and dynamical balance provided by a data assimilation system. Furthermore, it is not even clear how radiosonde temperatures are related to the actual water vapor mixing ratio of air entering the stratosphere, since that air may initially contain some ice crystals that may evaporate (thereby moistening the air), grow by turbulent mixing in a radiatively destabilized cloud [Danielsen, 1982], or mostly precipitate before evaporating [Knollenberg et al., 1993].

HALOE $\hat{H}$ and MLS $q$ data shed new light on the role of mixing in modifying the tape signal. In particular, our analysis implies that vertical mixing is weak and that the subtropical stratospheric "transport barriers" [e.g., McIntyre, 1990, Norton, 1994, Polvani et al., 
1995] are effective at inhibiting transport into the tropics. The $H$ and $q$ data demonstrate such inhibition (section 3.3) for the tropical lower stratosphere, especially between about 50 and $20 \mathrm{hPa}$. An important corollary is the greater relevance, to the modeling of longlived tracer transport and tracer correlations, of "tropical pipe models" [Plumb, 1996], as contrasted with one-dimensional "global-mixing models" [Holton, 1986, Mahlinan et al., 1986, Plumb and Ko, 1992]. Hence the situation is unlike the one-dimensional, globally integrated, vertically diffusive situation studied most recently by Plumb and Ko [1992], which arises in the limit of fast meridional mixing. Plumb [1996] suggested on the basis of earlier evidence that the real tropical stratospherc is for chemical purposes closer to the limit of slow mixing, and he called it a "pipe"; we might add that it is rather like a "leaky pipe." Our estimates of an upper bound for $K_{z}$ and a lower bound for the mixing-in timescale (about $0.04 \mathrm{~m}^{2} \mathrm{~s}^{-1}$ and 7-9 months, respectively, in the altitude range $100-46 \mathrm{hPa}$, and about 0.06 $\mathrm{m}^{2} \mathrm{~s}^{-1}$ and $15-18$ months in the altitude range $46-10$ hPa) imply that the actual $K_{z}$ is much smaller and/or that the mixing-in timescale is much longer.

As is demonstrated by the THIN AIR model, the QBO can change the speed of the tape slightly, reducing or increasing parcel transit times to the middle stratosphere by about a month. Given the zonal mean winds during the UARS period, this reduction or increase partly explains the small discrepancies between the TEM calculation and the timing of minima and maxima in the UARS record, particularly MLS.

Taken together and accounting for the apparent bias in MLS measurements, the UARS instruments imply an annually varying $q_{\mathrm{E}}$ whose annual average is about $3.5 \mathrm{ppmv}$, assuming negligible methane oxidation between the tropopause and $46 \mathrm{hPa}$. A value of $3.5 \mathrm{ppmv}$ is in agreement with an estimate of $3.25 \mathrm{ppmv}$ using LIMS and SAMS data [Hansen and Robinson, 1989] and with a careful estimate (2.9-3.4 ppmv) using HALOE data (E. Remsberg et al., Estimates of the water vapor budget of the stratosphere from UARS HALOE data, submitted to Journal of Geophysical Research, 1995) but somewhat lower than recent estimates using aircraft data: Dessler et al. [1994] derived a value of 4.2 ppmv, and Weinstock et al. [1995] derived a value of 4.4 ppniv. Remsberg et al., however, note that because of its history, air at aircraft flight level may not yield an accurate estimate of annual mean $q_{\mathbf{E}}$.

Acknowledgments. We thank Ken Kelly, George Reid and Er-Woon Chiou for supplying, respectively, the ER-2 water vapor data, the Koror radiosonde temperature and pressure time series, and the SAGE II water vapor retrievals. We are also grateful to members of the MLS, HALOE, and CLAES science teams for processing the data, and to Richard Swinbank of the UK Met. Office for useful discussions about the UKMO assimilation. Bob Harwood, Adrian Tuck, and two anonymous reviewers supplied helpful com- ments, and we are particularly grateful to the reviewer who urged a more quantitative treatment of mixing in section 3.3. We also wis in to thank Kristie Boering, Eleanor Highwood, Ken Minschwaner, Jöelle Ovarlez, Ellis Remsberg, and Holger Vömel for showing us their unpublished work. M.E.M. is funded by a UK Engineering and Physical Sciences Research Council Senior Research Fellowship. Work at Edinburgh is funded by the UK Natural Environment Research Council (NERC), including support for P.W.M. through the UK Universities' Global Atmospheric Modelling Programme. Further support, including publication costs, was provided by NASA contract NAS5-26301 (UARS).

\section{References}

Atticks, M. G., and G. D. Robinson, Some features of the structure of the tropical tropopause, $Q$. J. R. Meteorol. Soc., 109, 295-308, 1983.

Avallone, L.M., and M.J. Prather, Photochemical evolution of ozone in the lower tropical stratosphere, J. Geo. phys. Res., in press, 1996.

Barath, F.T., et al., The Upper Atmosphere Research Satellite microwave limb sounder instrument, J. Geophys. Res., $98,10,751-10,762,1993$.

Boering, K.A., et al., Measurements of carbon dioxide and water vapor at northern midlatitudes: Implications for troposphere-to-stratosphere exchange, Geophys. Res. Lett., 22, 2737-2740, 1995.

Carr, E.S., et al., Tropical stratospheric water vapor measured by the microwave limb sounder (MLS), Geophys. Res. Lctt., 22, 691-694, 1995.

Chen, P., J. R. Holton, A. O'Neill, and R. Swinbank, Isentropic mass exchange between the tropics and extratropics in the stratosphere, J. Atmos. Sci., 51, 3006-3018, 1994.

Danielsen, E.F., A dehydration mechanism for the stratosphere, Geophys. Res. Lett., 9, 605-608, 1982.

Dessler, A.E., E.M. Weinstock, E.J. Hintsa, J.G. Anderson, ( .R. Webster, R.D. May, J.W. Elkins, and G.S. Dutton, An examination of the total hydrogen budget of the lower stratosplire, Geophys. Res. Lett., 21, 2563-2566, 1994.

Dewan, E.M., Turbulent vertical transport due to thin intermittent mixing layers in the stratosphere and other stable fluids, Science, 211, 1041-1042, 1981.

Feely, H.W., and J. Spar, Tungsten-185 from nuclear bomb tests as a tracer for stratospheric meteorology, Nature, $188,1062-1064,1960$.

Frederick, J.E., and A.R. Douglass, Atmospheric temperatures near the tropical tropopause: Temporal variations, zonal asymmetry and implications for stratospheric water vapor, Mon. Weather Rev., 111, 1397-1403, 1983.

Garcia, R.R., Parameterization of planetary wave breaking in the middle atmosphere, J. Atmos. Sci., 48, 1405-14:9, 1991.

Gille, J.C., and J.M. Russell III, The Limb Infrared Monitor of the Stratosphere: Experiment description, performance, and results, J. Gcophys. Res., 89, 5125-5140, 1984.

Hansen, A.R., and G.D. Robinson, Water vapor and methane in the upper stratosphere: An examination of some of the Nimbus 7 measurements, J. Geophys. Res., 94, 84748484, 1989.

Haynes, P.H., M.E. McIntyre, and T.G. Shepherd, Reply to Comment by J. Egger, J. Atmos. Sci., in press, 1996.

Hintsa, E.J., E.M. Weinstock, A.E. Dessler, J.G. Anderson, M. Loewenstein, and J.R. Podolske, SPADE $\mathrm{H}_{2} \mathrm{O}$ mea- 
surements and the seasonal cycle of stratspheric water vapor, Geophys. Res. Lett., 21, 2559-2562, 1994.

Holton, J.R., Troposphere-stratosphere exchange of trace constituents: The water vapor puzzle, in Dynamics of the Middle Atmosphere, edited by J.R. Holton and T. Matsuno, pp. 369-385, Terra Sci., Tokyo, 1984.

Holton, J.R., A dynamically based transport parameterization for one-dimensional photochemical models of the stratosphere, J. Geophys. Res., 91, 2681-2686, 1986.

Holton, J.R., P.H. Haynes, M.E. McIntyre, A.R. Douglass, R.B. Rood, and L. Pfister, Stratosphere-troposphere exchange. Rev. Geophys., 33(4), 405-439, 1995.

Hyson, P., Stratospheric water vapour over Australia, Q. J. R. Meteorol. Soc., 109, 285-294, 1983.

Jones, R.L., J.A. Pyle, J.E. Harries, A.M. Zavody, J.M. Russell III, and J.C. Gille, The water vapour budget of the stratosphere studied using LIMS and SAMS satellite data, Q. J. R. Meteorol. Soc., 112, 1127-1143, 1986.

Juckes, M.N., and M.E. McIntyre, A high resolution, onelayer model of breaking planetary waves in the stratosphere, Nature, 328, 590-596, 1987.

Kelly, K.K., et al., Dehydration in the lower Antarctic stratosphere during late winter and early spring $1987, J$. Geophys. Res., 94, 11,317-11,357, 1989.

Kelly, K.K., M. H. Proffitt, K. R. Chan, M. Loewenstein, J. R. Podolske, S. E. Strahan, J. C. Wilson, and D. Kley, Water vapor and cloud water measurements over Darwin during the STEP 1987 tropical mission, J. Geophys. Res., $98,8713-8723,1993$

Kinnersley, J.S., A realistic three-component planetary wave model, with a wave breaking parametrisation. Q. J. R. Meteorol. Soc., 121(b), 853-881, 1995.

Kinnersley, J.S., The climatology of the stratospheric THIN AIR model, Q. J. R. Meteorol. Soc., in press, 1996.

Kinnersley, J.S., and R.S. Harwood, An isentropic twodimensional model with an interactive parametrisation of dynamical and chemical planetary-wave fluxes. Q. J. R. Meteorol. Soc., 119, 1167-1193, 1993.

Kinusersley, J.S., and S. Pawson, On the descent rates of the shear zones of the equatorial QBO, J. Atmos. Sci.., in press, 1996

Kley, D., E.J. Stone, W.R. Henderson, J.W. Drummond, W.J. Harrop, A.L. Schmeltekopf, 'T.L. 'Thompson, and R.H. Winkler, In situ measurements of the mixing ratio of water vapor in the stratosphere, J. Atmos. Sci., 36 2513-2524, 1979.

Kley, D., A.L. Schmeltekopf, K. Kelly, R.H. Winkler T.L. Thompson, and M. McFarland, Transport of water through the tropical tropopause, Gecishys. Res. Lett., 9, 617-620, 1982.

Knollenberg, R.G., K. Kelly, and J.C. Wilson, Measurements of high number densities of ice crystals in the tops of tropical cumulonimbus, J. Geophys. Res., 98, 8639-8664, 1993.

Krishna Murthy, B.V., K. Parameswaran, and K.O. Rose, Temporal variations of the tropical tropopause characteristics, J. Atmos. Sci., 43, 914-922, 1986.

Kritz, M.A., S.W. Rosner, K.K. Kelly, M. Loewenstein, and K.R. Chan, Radon measurements in the lower tropical stratosphere: Evidence for rapid vertical transport and dehydration of tropospheric air, J. Geophys. Res., 98, $8725-8736,1993$.

Lahoz, W.A., et al., Validation of UARS microwave limb sounder $183 \mathrm{GHz} \mathrm{H}_{2} \mathrm{O}$ measurements, J. Geophys. Res. in press, 1996.

Mahlman, J.D., H. Levy II, and W.J. Moxim, Three-dimensional simulations of stratospheric $\mathrm{N}_{2} \mathrm{O}$ : Predictions for other trace constituents, J. Geophys. Res., 91, 2687-2707, 1986. (Correction, J. Geophys. Res., 91, 9921, 1986.)
Mastenbrook, H.J., Water vapor distribution in the stratosphere and high troposphere, J. Atmos. Sci. 25, 299-311, 1968.

Mastenbrook, H.J., and S.J. Oltmans, Stratospheric water vapor variability for Washington, DC/Boulder, CO: 19641982, J. Atmos. Sci. 40, 2157-2165, 1983.

McCormick, M.P., E.W. Chiou, L.R. McMaster, W.P. Chu, J.C. Larsen, D. Rind, and S. Oltmans, Annual variations of water vapor in the stratosphere and upper troposphere observed by the Stratospheric Aerosol and Gas Experiment II, J. Geophys. Res., 98, 4867-4874, 1993.

McIntyre, M.E., Middle atmospheric dynamics and transport: Some current challenges to our understanding, in Dynamics, Transport and Photochemistry in the Middle Atmosphere of the Southern Hemisphere, (Proc. San Francisco NATO Workshop), edited by A. O'Neill, pp. 1-18, Kluwer Acad., Norwell, Mass., 1990.

Mote, P.W., Reconsideration of the cause of dry air in the southern middle latitude stratosphere, Geophys. Res. Lett., 22, 2025-2028, 1995.

Mote, P.W., K.H. Rosenlof, J.R. Holton, R.S. Harwood, and J.W. Waters, Seasonal variations of water vapor in the tropial lower stratosphere. Geophys. Res. Lett., 22, 1093$1096,1995$.

Newell, R.E., and S. Gould-Stewart, A stratospheric fountain? J. Atmos. Sci., 38, 2789-2796, 1981.

Norton, W. A., Breaking Rossby waves in a model stratosphere diagnosed by a vortex-following coordinate system and a tecinique for advecting material contours. $J$. Atmos. Sci., 51, 654-673, 1994.

Plumb, R.A., A "tropical pipe" model of stratospheric transport, J. Geophys. Res., in press, 1996.

Plumb, R.A., and M.K.W. Ko, Interrelationships between mixing ratios of long-lived stratospheric constituents, J. Geophys. Res., 97, 10,145-10,156, 1992.

Polvani, I.M., D.W. Waugh, and R.A. Plumb, On the subtropical edge of the stratospheric surf zone, J. Atmos. Sci., 52, 1288-1309, 1995

Reid, G. C., and K. S. Gage, On the annual variation in height of the tropical tropopause, J. Atmos. Sci., 38, $1928-1938,1981$

Rind, D., E.-W. Chiou, W. Chu, S. Oltu.ans, J. Lerner, J. Larsen, M. P. McCormick, and L. McMaster, Overview of the Stratospheric Aerosol and Gas Experiment II water vapor observations: Method, validation, and data characteristics, J. Geophys. Res., 98, 4835-4856, 1993.

Roche, A.E., J.B. Kumer, J.L. Mergenthaler, G.A. Ely, W.G. Uplinger, J.F. Potter, T.C. James, and L.W. Sterritt, The Cryogenic Limb Array Etalon Spectrometer (CLAES) on UARS: Experiment description and performance, J. Geophys. Res., 98, 10,763-10,775, 1993

Rosenlof, K.H., Seasonal cycle of the residual mean meridional circulation in the stratosphere, J. Geophys. Res., $100,5173-5191,1995$.

Rosenlof, K.H., and J.R. Holton, Estimates of the stratospheric residual circulation using the downward control principle, J. Geophys. Res., 98, 10,465-10,479, 1993.

Russell, J.M. III, L.L. Gordley, J.H. Park, S.R. Drayson, W.D. Hesketh, R.J. Cicerone, A.F. Tuck, J.E. Frederick, J.E. Harries, and P.J. Crutzen, The Halogen Occultation Experiment, J. Geophys. Res., 98, 10,777-10,798, 1993.

Shine, K.P., Sources and sinks of zonal momentum in the middle atmosphere diagnosed using the diabatic circulation. Q. J. Roy. Meteorol. Soc., 115, 265-292, 1989.

Swinbank, R., and A. O'Neill, Quasi-biennial and semiannual oscillations in equatorial wind fields constructed by data assimilation, Gcophys. Res. Lett., 21, 2099-2102, 1994

Trepte, G.R., and M.H. Hitchman, Tropical stratospheric 
circulation deduced from satellite aerosol data, Nature, $355,626-628,1992$.

Vömel, H., S.J. Oltmans, D. Kley, and P.J. Crutzen, New evidence for the stratospheric dehydration mechanism in the equatorial Pacific, Geophys. Res. Lett., in press, 1995.

Waters, J.W., Microwave limb sounding, in Atmospheric Remote Sensing by Microwave Radiometry, edited by M.A. Janssen, chap. 8, pp. 383-496, New York: John Wiley, 1993.

Waugh, D.W., Seasonal variation of isentropic transport out of the tropical stratosphere, J. Geophys. Res., in press, 1996.

Weinstock, E.M., E.J. Hintsa, A.E. Dessler, and I.G. Anderson, Measurements of water vapor in the tropical lower stratosphere during the CEPEX campaign: Results and interpretation, Geophys. Res. Lett., in press, 1995.

World Meteorological Organization (WMO), Ozone assessment report, 1985, Geneva, 1986.

Yulaeva, E., J.R. Holton, and J.M. Wallace, On the cause of the annual cycle in tropical lower stratospheric temperatures, J. Atmos. Sci., 51, 169-174, 1994.

E.S. Carr, Logica UK Ltd., 67-75 Hampstead Rd., London NW: 2PL, England.
J.C. Gille, Atmospheric Chemistry Division, National Center for Atmospheric Research, Boulder, CO 80307.

J.R. Holton, Department of Atmospheric Sciences, Box 351640, University of Washington, Seattle WA 98195-1640.

J.S. Kinnersley, Department of Applied Mathematics, Box 352420, University of Washington, Seattle WA 98195-2420.

M.E. McIntyre, Department of Applied Mathematics and Theoretical Physics, Cambridge University, CB3 9EW, England. (Internet http://www.damtp.cam.ac.uk/atmosdynamics)

P.W. Mote and H. C. Pumphrey, Dept. of Meteorology, King's Buildings, University of Edinburgh, Edinburgh EH9 3JZ, Scotland (e-mail: mote@met.ed.ac.uk).

K.H. Rosenlof, Cooperative Institute for Research in Environmental Sciences, University of Colorado, Boulder, CO 80303.

J.M. Russell III, NASA Langley Research Center, Hampton VA 23665.

J.W. Waters, Jet Propulsion Laboratory, California Institute of Technology, 4800 Oak Grove Drive, Pasadena, CA 91109-8099.

(Received April 3, 1995; revised October 26, 1995; accepted October 26, 1995) 